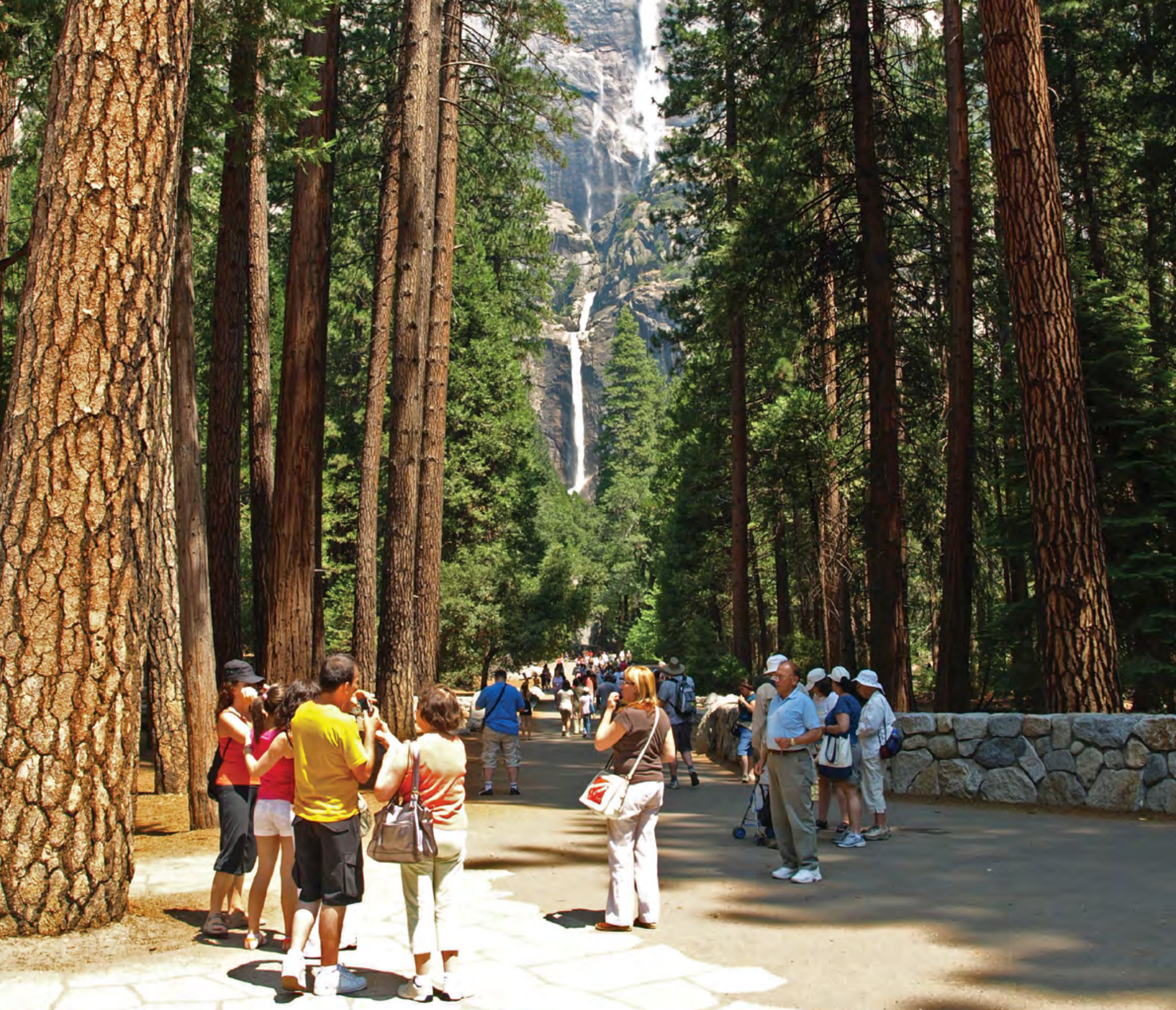

CHAPITRE 23

\title{
GESTION DES VISITEURS
}

\section{Auteurs principaux :}

Anna Spenceley, Jon Kohl, Simon McArthur, Peter Myles, Marcello Notarianni, Dan Paleczny, Catherine Pickering et Graeme L. Worboys

\section{TABLE DES MATIÈRES}

- Introduction

- L'impératif de conservation

- Gestion des visiteurs

- Gestion du tourisme

- Gestion des options de loisirs

- Services et installations destinés aux visiteurs

- Gestion de l'impact des visiteurs

- Conclusion

- Références

UICN CMAP 


\section{AUTEURS PRINCIPAUX}

ANNA SPENCELEY est consultante, basée en Afrique du Sud, présidente du groupe de spécialistes du tourisme et des aires protégées de la Commission mondiale des aires protégées (CMAP) de l'Union internationale pour la conservation de la nature (UICN) et membre du groupe d'experts du Partenariat mondial pour le tourisme durable.

JON KOHL, basé au Costa Rica, est coordinateur facilitateur du Public Use Planning Global Heritage Consortium et spécialiste de l'interprétation du patrimoine et de la conception de l'expérience des visiteurs.

SIMON MCARTHUR est consultant, basé en Australie, et travaille sur la planification, la faisabilité et le développement du tourisme d'intérêt spécial. II a développé des modèles de tourisme durable en Chine, aux Bahamas, en Australie et au Canada.

PETER MYLES est basé en Afrique du Sud, enregistré auprès de l'Organisation mondiale du tourisme des Nations unies (OMT) en tant que collaborateur touristique, et membre du comité directeur ayant fondé l'International Coastal and Marine Tourism Society.

MARCELLO NOTARIANNI est consultant, basé en Italie, avec plus de 16 ans d'expérience dans le développement durable du tourisme. Il est expert auprès de l'OMT, de la CMAP-UICN et de l'Organisation internationale du travail (OIT).

DAN PALECZNY est directeur des politiques, de la planification et des relations autochtones au Ministère de l'environnement du Yukon, Canada, et membre du groupe de spécialistes du tourisme et des aires protégées de la CMAP.

CATHERINE PICKERING est professeure au Environnemental Future Research Institute de l'Université de Griffith, Australie.

GRAEME L. WORBOYS est co-vice-président pour la conservation de la connectivité et les montagnes de l'UICN-CMAP, et chercheur associé à la Fenner School de l'Université nationale australienne.

\section{REMERCIEMENTS}

Pema Bhutia et Katherine Turner ont préparé les études de cas de ce chapitre. Nous sommes reconnaissants pour l'utilisation d'extraits d'études de recherche sur la faune et les aires protégées publiées par le Sustainable Tourism Cooperative Research Centre, Australie.

\section{CITATION}

Spenceley, A., Kohl, J., McArthur, S., Myles, P., Notarianni, M., Paleczny, D., Pickering, C. et Worboys, G. L. Visitor management. In Worboys, G. L., Lockwood, M., Kothari, A., Feary, S. et Pulsford, I. (éd.) Gouvernance et gestion des aires protégées. Canberra : ANU Press, 2020. doi.org/10.22459/GGAP.23

\section{PHOTO DE LA PAGE DE TITRE}

Visiteurs aux chutes du Yosemite, parc national du Yosemite, États-Unis

Source : Graeme L. Worboys

\section{(P) CMAP}




\section{Introduction}

Il existe de nombreux types de visiteurs dans les aires protégées. Il peut s'agir, par exemple, d'invités officiels dans un parc national, de chercheurs travaillant dans une réserve naturelle intégrale, de bénévoles participant à un programme de travail dans un parc national, de groupes éducatifs se renseignant sur le patrimoine naturel ou culturel spécial, ou de personnes pratiquant leurs activités dans une aire protégée, y compris des entrepreneurs et des propriétaires de boutiques. Il est important de noter que les visiteurs incluent également des touristes et des amateurs de loisirs en plein air. Dans ce chapitre, nous examinerons brièvement les types de visiteurs que les gestionnaires d'aires protégées peuvent avoir à gérer et les considérations de gestion associées à cette utilisation par les visiteurs. Cependant, ce chapitre mettra l'accent sur le tourisme et sa gestion. En fonction des différentes catégories d'aires protégées de l'Union internationale pour la conservation de la nature (UICN), le tourisme et les loisirs peuvent constituer des utilisations courantes de la plupart des aires protégées par les visiteurs, et contribuent de manière importante aux économies locales et nationales. Dans le cadre de la gestion des aires protégées pour les touristes, nous décrirons un cadre de gestion permettant d'offrir toute une gamme d'options de loisirs dans les réserves, la prestation de services et d'installations destinés aux visiteurs et les réponses de gestion aux impacts des visiteurs.

\section{L'impératif de conservation}

L'Union internationale pour la conservation de la nature (UICN) a facilité l'élaboration d'une définition internationalement acceptée des aires protégées. Cette définition stipule qu'une aire protégée est " un espace géographique clairement défini, reconnu, dédié et géré, par des moyens légaux ou autres moyens efficaces, pour assurer la conservation à long terme de la nature ainsi que des services écosystémiques et valeurs culturelles associés " (Dudley, 2008:8).

Chaque mot de cette définition est important (voir chapitre 2) et fournit des orientations solides pour la gestion du tourisme dans les aires protégées. Plus précisément, le terme " dédié " fait référence à un engagement contraignant en faveur de la conservation de la nature à long terme pour l'aire protégée, et " géré " signifie que des mesures actives sont prises pour conserver les valeurs naturelles (et éventuellement d'autres valeurs) pour lesquelles l'aire protégée a été créée. En outre, le terme " long terme " reconnaît que les aires protégées doivent être gérées à perpétuité, et non comme une stratégie de gestion à court terme ou temporaire, et le terme « nature » fait toujours référence à la biodiversité, à l'échelle génétique, des espèces et des écosystèmes, et inclut souvent la géodiversité, c'est à dire les formes de relief et les valeurs naturelles plus générales (Dudley, 2008). Les "valeurs culturelles » incluent toute celles n’interférant pas avec les principaux résultats en matière de conservation de la biodiversité (Dudley, 2008).

Cette définition guide la gestion des visiteurs et du tourisme dans les aires protégées et, s'inspirant de Dudley (2008), les principes suivants s'appliquent :

- la conservation de la biodiversité et autres aspects de la nature a primauté dans toutes les décisions ;

- toute pratique d'exploitation ou de gestion qui nuirait aux objectifs de la désignation doit être évitée ou éliminée, si nécessaire ;

- la gestion des visiteurs et du tourisme doit être guidée par un plan de gestion et un programme de suivi et d'évaluation qui soutienne la gestion adaptative.

L'utilisation des aires protégées par les visiteurs fait partie intégrante de leur fonctionnement quotidien (tableaux 23.1 et 23.2). L'utilisation par les visiteurs offre des possibilités d'éducation, procure des avantages récréatifs, favorise le soutien du public à la protection et peut offrir des avantages aux résidents et aux communautés locales, conformément aux autres objectifs de gestion (Dudley, 2008). Cette utilisation peut prendre la forme d'activités de recherche scientifique à faible impact ou de suivi écologique, liées et compatibles avec les valeurs de l'aire protégée, dans toutes les catégories d'aires protégées de l'UICN (Dudley, 2008). Pour certaines catégories d'aires protégées, le tourisme procure des avantages économiques essentiels. Les aires protégées de catégorie II de l'UICN, en particulier, offrent des possibilités d'utilisation pour les visiteurs et le tourisme. L'UICN

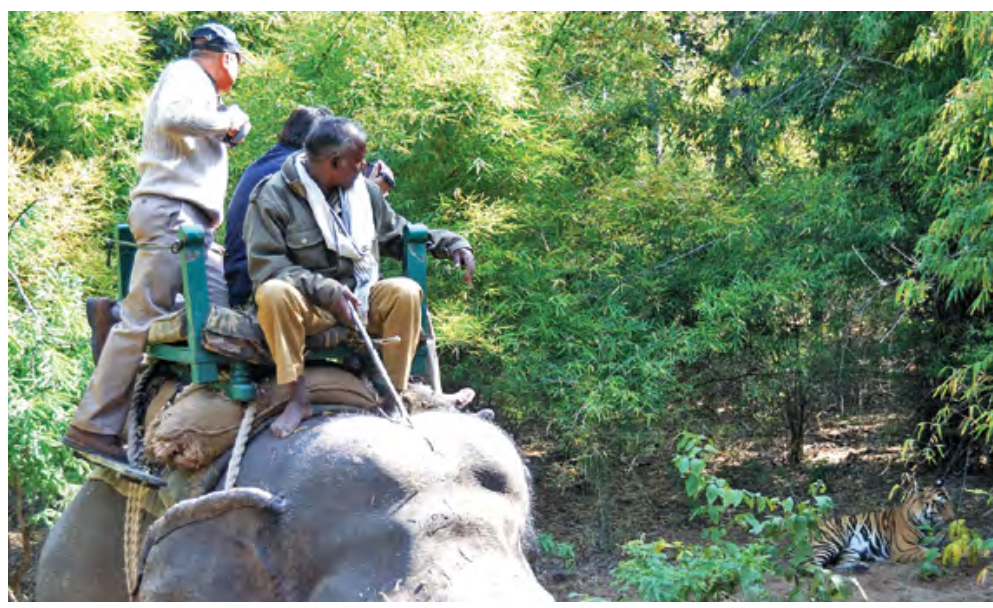

Les questions de sécurité des visiteurs sont essentielles. Observation d'un tigre sauvage du Bengale (Panthera tigris) depuis un éléphant (Elephas maximus), parc national de Bandhavgarh, Inde

Source : Ashish Kothari 
auront généralement des besoins spéciaux. Cela peut inclure des services de soutien spéciaux tels que l'accès, le transport, les services publics, la sécurité et des besoins administratifs spécifiques. En plus de cette "utilisation officielle " par les communautés autochtones et locales et les organismes chargés de la gestion des aires protégées (tableau 23.1), l'utilisation des aires protégées par les visiteurs, y compris pour le tourisme, aide les gestionnaires à protéger, conserver et apprécier les valeurs pour lesquelles une aire protégée a été établie (tableau 23.2). L'utilisation des aires protégées constitue une considération culturelle (voir les chapitres 4 et 22), et un certain nombre de types d'utilisation sont jugés appropriés. L'UICN reconnaît six catégories d'aires protégées dont les objectifs de gestion aident à définir le but de chaque réserve (voir les chapitres 2 et 8 ). Cela aide à déterminer les types d'utilisation des visiteurs convenant le mieux à une aire protégée donnée (tableau 23.2) (Dudley, 2008). Le tourisme, par exemple, est généralement une caractéristique particulière des aires protégées de catégorie II de l'UICN, bien qu'il soit subordonné aux principaux objectifs de conservation du patrimoine de ces sites. Le tourisme, lui-même, regroupe un large éventail d'utilisations (tableau 23.2).

Tableau 23.1 Types de visiteurs officiels dans les aires protégées (y compris les aires du patrimoine autochtone et communautaire et les aires protégées privées)

\begin{tabular}{|c|c|c|c|c|c|c|c|}
\hline \multirow[t]{2}{*}{ Visiteurs } & \multirow[t]{2}{*}{ But de la visite } & \multicolumn{6}{|c|}{$\begin{array}{c}\text { Catégories d'aires protégées } \\
\text { de l'UICN. }\end{array}$} \\
\hline & & I & II & III & IV & $\mathbf{V}$ & VI \\
\hline $\begin{array}{l}\text { Membres de } \\
\text { communautés } \\
\text { responsables d'une } \\
\text { aire protégée. }\end{array}$ & $\begin{array}{l}\text { Tous les aspects de la gestion de la conservation d'une } \\
\text { aire protégée communautaire et des terres autochtones. }\end{array}$ & $\checkmark$ & $\checkmark$ & $\checkmark$ & $\checkmark$ & $\checkmark$ & $\checkmark$ \\
\hline $\begin{array}{l}\text { Membres de } \\
\text { communautés locales, } \\
\text { peuples autochtones } \\
\text { ou opérateurs privés } \\
\text { impliqués dans une } \\
\text { aire protégée. }\end{array}$ & $\begin{array}{l}\text { Communauté ancestrale ou traditionnelle potentielle } \\
\text { ou entreprise touristique privée avec utilisation durable } \\
\text { officielle et approuvée des ressources naturelles } \\
\text { provenant (respectivement) d'une aire autochtone ou } \\
\text { conservée par la communauté, ou d'une aire protégée } \\
\text { privée. Cela peut inclure l'élevage de rennes, la pêche } \\
\text { et la chasse (avec des niveaux convenus de captures } \\
\text { de poissons ou des quotas de chasse privée). }\end{array}$ & $\checkmark$ & $\checkmark$ & $\checkmark$ & $\checkmark$ & $\checkmark$ & $\checkmark$ \\
\hline $\begin{array}{l}\text { Gestionnaire de l'aire } \\
\text { protégée. }\end{array}$ & $\begin{array}{l}\text { Planification, suivi, recherche, réponse aux menaces, } \\
\text { réponse aux incidents, application de la loi, gestion des } \\
\text { visiteurs. }\end{array}$ & $\checkmark$ & $\checkmark$ & $\checkmark$ & $\checkmark$ & $\checkmark$ & $\checkmark$ \\
\hline $\begin{array}{l}\text { Travailleur de l'aire } \\
\text { protégée. }\end{array}$ & $\begin{array}{l}\text { Mise en œuvre de programmes de travail, tels que la lutte } \\
\text { contre les animaux nuisibles, y compris la chasse, la } \\
\text { lutte contre les mauvaises herbes, la lutte contre les } \\
\text { incendies et la restauration de l'érosion des sols. }\end{array}$ & $\checkmark$ & $\checkmark$ & $\checkmark$ & $\checkmark$ & $\checkmark$ & $\checkmark$ \\
\hline $\begin{array}{l}\text { Prestataires de l'aire } \\
\text { protégée. }\end{array}$ & $\begin{array}{l}\text { Programme de travail délégué, mis en œuvre au nom } \\
\text { d'une organisation chargée des aires protégées. }\end{array}$ & $\checkmark$ & $\checkmark$ & $\checkmark$ & $\checkmark$ & $\checkmark$ & $\checkmark$ \\
\hline Personnel militaire. & $\begin{array}{l}\text { Programme délégué pour protéger les ressources de } \\
\text { conservation du patrimoine. }\end{array}$ & $\checkmark$ & $\checkmark$ & $\checkmark$ & $\checkmark$ & $\checkmark$ & $\checkmark$ \\
\hline $\begin{array}{l}\text { Personnel des services } \\
\text { communautaires. }\end{array}$ & $\begin{array}{l}\text { Personnel d'organisations telles que la police, les } \\
\text { pompiers ou les ambulances, ayant un rôle officiel dans } \\
\text { l'aire protégée. }\end{array}$ & & $\checkmark$ & $\checkmark$ & & $\checkmark$ & $\checkmark$ \\
\hline Locataire. & $\begin{array}{l}\text { Personne ou société détenant un droit légal } \\
\text { d'entreprendre une certaine utilisation de l'aire } \\
\text { protégée, telle que l'hébergement ou les services de } \\
\text { guides. }\end{array}$ & & $\checkmark$ & $\checkmark$ & & & \\
\hline Détenteur de licence. & $\begin{array}{l}\text { Personne ou entreprise détenant un droit légal de fournir } \\
\text { des services dans une aire protégée, tels que le transport } \\
\text { des visiteurs ou l'élimination des déchets. }\end{array}$ & & $\checkmark$ & $\checkmark$ & & & \\
\hline $\begin{array}{l}\text { Personnes très } \\
\text { importantes (VIP). }\end{array}$ & $\begin{array}{l}\text { Invité(s) officiel(s) d'un gouvernement, de l'organisation } \\
\text { chargée de l'aire protégée, ou de l'administration des } \\
\text { aires protégées. }\end{array}$ & $\checkmark$ & $\checkmark$ & $\checkmark$ & $\checkmark$ & $\checkmark$ & $\checkmark$ \\
\hline
\end{tabular}


Tableau 23.2 Utilisation indicative des aires protégées par les visiteurs

\begin{tabular}{|c|c|c|c|c|c|c|c|}
\hline \multirow[t]{2}{*}{ Type de visiteur } & \multirow[t]{2}{*}{ Type d'utilisation par les visiteurs } & \multicolumn{6}{|c|}{$\begin{array}{l}\text { Catégories d'aires protégées de } \\
\text { l'UICN. }\end{array}$} \\
\hline & & i & if & mif & iv & $\mathbf{v}$ & vi \\
\hline \multirow{7}{*}{$\begin{array}{l}\text { Bénévoles (officiellement } \\
\text { reconnus et soutenus) }\end{array}$} & Pompiers et personnel de recherche et de sauvetage. & $\checkmark$ & $\checkmark$ & $\checkmark$ & $\checkmark$ & $\checkmark$ & $\checkmark$ \\
\hline & Entretien et restauration de sites historiques. & & $\checkmark$ & $\checkmark$ & $\checkmark$ & $\checkmark$ & $\checkmark$ \\
\hline & Entretien des chemins de randonnée. & & $\checkmark$ & $\checkmark$ & $\checkmark$ & $\checkmark$ & $\checkmark$ \\
\hline & Élimination de plantes introduites. & $\checkmark$ & $\checkmark$ & $\checkmark$ & $\checkmark$ & $\checkmark$ & $\checkmark$ \\
\hline & $\begin{array}{l}\text { Protection de la faune, comme la surveillance et } \\
\text { la protection des sites de nidification des oiseaux } \\
\text { saisonniers. }\end{array}$ & $\checkmark$ & $\checkmark$ & $\checkmark$ & $\checkmark$ & & \\
\hline & $\begin{array}{l}\text { Soutien au services destinés aux visiteurs, comme les } \\
\text { gardiens de camping bénévoles ou les guides. }\end{array}$ & & $\checkmark$ & $\checkmark$ & & $\checkmark$ & $\checkmark$ \\
\hline & $\begin{array}{l}\text { Chercheurs, comme ceux effectuant une évaluation } \\
\text { de la biodiversité. }\end{array}$ & $\checkmark$ & $\checkmark$ & $\checkmark$ & $\checkmark$ & $\checkmark$ & $\checkmark$ \\
\hline $\begin{array}{l}\text { Chercheurs } \\
\text { (officiellement autorisés) }\end{array}$ & $\begin{array}{l}\text { Tous les aspects de la recherche sur le patrimoine } \\
\text { naturel, y compris la mesure des conditions de } \\
\text { référence, les tendances de ces conditions et des } \\
\text { processus écosystémiques, et la recherche sur le } \\
\text { patrimoine social et culturel. }\end{array}$ & $\checkmark$ & $\checkmark$ & $\checkmark$ & $\checkmark$ & $\checkmark$ & $\checkmark$ \\
\hline \multirow{2}{*}{$\begin{array}{l}\text { Utilisateurs } \\
\text { commerciaux } \\
\text { (officiellement autorisés) }\end{array}$} & Cinéastes naturalistes. & & $\checkmark$ & & & $\checkmark$ & $\checkmark$ \\
\hline & $\begin{array}{l}\text { Services d'accès destinés aux visiteurs, y compris } \\
\text { animaux de bât, vélos, taxis, autobus, avions, } \\
\text { embarcations à moteur, motoneiges, et autres. }\end{array}$ & & $\checkmark$ & & & $\checkmark$ & $\checkmark$ \\
\hline \multirow{11}{*}{$\begin{array}{l}\text { Touristes et amateurs } \\
\text { de loisirs en plein air } \\
\text { (utilisation durable) }\end{array}$} & Visiteurs intéressés par l'éducation. & & $\checkmark$ & $\checkmark$ & $\checkmark$ & $\checkmark$ & $\checkmark$ \\
\hline & Tourisme automobile, vélo, photographie, peinture. & & $\checkmark$ & $\checkmark$ & & $\checkmark$ & $\checkmark$ \\
\hline & Pique-nique, marche, randonnée, camping. & & $\checkmark$ & $\checkmark$ & & $\checkmark$ & $\checkmark$ \\
\hline & Étude de la nature et sensibilisation culturelle. & & $\checkmark$ & & & $\checkmark$ & $\checkmark$ \\
\hline & Courses d'orientation, cross-country. & & $\checkmark$ & & & $\checkmark$ & $\checkmark$ \\
\hline & $\begin{array}{l}\text { Utilisation des itinéraires officiels d'équitation, } \\
\text { VTT, } 4 \times 4 \text { et moto. }\end{array}$ & & $\checkmark$ & & & $\checkmark$ & $\checkmark$ \\
\hline & $\begin{array}{l}\text { Utilisation durable (comme la pêche ou la chasse } \\
\text { autorisée dans le cadre de la gestion des aires } \\
\text { protégées privées). }\end{array}$ & & & & & & $\checkmark$ \\
\hline & $\begin{array}{l}\text { Vol non motorisé, deltaplane, parapente, montgolfière } \\
\text { autorisés. }\end{array}$ & & $\checkmark$ & & & $\checkmark$ & $\checkmark$ \\
\hline & $\begin{array}{l}\text { Activités nautiques, pêche, natation, bain de soleil, } \\
\text { canoë, canotage, voile, rafting. }\end{array}$ & & $\checkmark$ & & & $\checkmark$ & $\checkmark$ \\
\hline & $\begin{array}{l}\text { Skieurs, snowboardeurs et grimpeurs sur neige et sur } \\
\text { glace. }\end{array}$ & & $\checkmark$ & & & $\checkmark$ & $\checkmark$ \\
\hline & Alpinisme et spéléologie. & & $\checkmark$ & $\checkmark$ & & $\checkmark$ & $\checkmark$ \\
\hline $\begin{array}{l}\text { Utilisations culturelles et } \\
\text { spirituelles (officiellement } \\
\text { approuvées et } \\
\text { soutenues) }\end{array}$ & $\begin{array}{l}\text { Accès formel aux aires protégées pour des raisons } \\
\text { spirituelles, cérémonielles et culturelles, telles que les } \\
\text { voies d'accès traditionnelles. }\end{array}$ & $\checkmark$ & $\checkmark$ & $\checkmark$ & $\checkmark$ & $\checkmark$ & $\checkmark$ \\
\hline $\begin{array}{l}\text { Utilisations } \\
\text { commémoratives } \\
\text { (officiellement } \\
\text { approuvées et soutenues) }\end{array}$ & $\begin{array}{l}\text { Accès aux aires protégées à des fins } \\
\text { commémoratives, comme le retour de visiteurs } \\
\text { sur des sites d'importance culturelle dans une aire } \\
\text { protégée. }\end{array}$ & & $\checkmark$ & $\checkmark$ & & $\checkmark$ & $\checkmark$ \\
\hline
\end{tabular}




\section{Utilisateurs « clandestins »}

Certaines personnes qui visitent les aires protégées ne sont pas autorisées à le faire et ne veulent pas être détectées lorsqu'elles y sont présentes, y compris celles se livrant à des activités illégales et criminelles. Ces activités incluent la récolte non autorisée de ressources naturelles des aires protégées (braconnage, récolte de bois, agriculture), la culture de drogues telles que la marijuana, et les personnes non autorisées utilisant l'aire protégée comme un endroit pour vivre.

\section{Considérations de gestion}

L'utilisation officielle et l'utilisation des aires protégées par les visiteurs varient considérablement. Cela implique immédiatement toute une gamme de considérations de gestion (tableau 23.3). Lidentification de ces besoins de gestion de l'utilisation par les visiteurs met également en évidence un principe clé : les aires protégées devraient toujours être une destination naturelle protégée, lorsque cela est possible, incluant seulement une infrastructure limitée et discrète, destinée aux visiteurs ou autres utilisations. Les aires protégées de catégorie $\mathrm{V}$ sont bien entendu gérées différemment (voir chapitre 8). Des exceptions peuvent également se produire pour les aires protégées de catégorie I à IV pour des raisons de sécurité ou de logistique, telles que l'hébergement dans certaines des très grandes aires protégées de la faune africaine.

Tableau 23.3 Considérations relatives à la gestion des visiteurs pour les aires protégées

\begin{tabular}{|c|c|}
\hline $\begin{array}{l}\text { Considérations de } \\
\text { gestion }\end{array}$ & Notes \\
\hline \multicolumn{2}{|c|}{ Politiques et planification } \\
\hline Utilisation appropriée & $\begin{array}{l}\text { II existe une norme minimale acceptable en ce qui concerne les visites respectueuses } \\
\text { et l'utilisation officielle de chaque aire protégée conformément à ses valeurs, son but et ses } \\
\text { objectifs. Cela doit être articulé et communiqué. II s'agit d'un point particulièrement important } \\
\text { lorsque l'aire protégée accueille des résidents officiels. }\end{array}$ \\
\hline $\begin{array}{l}\text { Diversité des options de } \\
\text { loisirs }\end{array}$ & $\begin{array}{l}\text { Idéalement, une vaste gamme d'options de loisirs sera disponible pour une aire protégée } \\
\text { de catégorie II. Certaines d'entre elles incluront délibérément des destinations naturelles } \\
\text { non développées. }\end{array}$ \\
\hline Niveaux de service & $\begin{array}{l}\text { Les organisations chargées des aires protégées doivent identifier le niveau de service qu'elles } \\
\text { fourniront dans les différentes destinations des visiteurs. Cela sera généralement lié à une } \\
\text { évaluation de la gestion des risques, les catégories de la gamme des options de loisirs et les } \\
\text { limites du budget disponible. }\end{array}$ \\
\hline $\begin{array}{l}\text { Gestion des } \\
\text { approvisionnements et de la } \\
\text { demande }\end{array}$ & $\begin{array}{l}\text { Les stratégies de marketing auprès des visiteurs et leur influence sur la demande doivent } \\
\text { être directement liées à la capacité de fournir une destination fiable et de haute qualité. }\end{array}$ \\
\hline $\begin{array}{l}\text { Développement économique } \\
\text { compatible }\end{array}$ & $\begin{array}{l}\text { Les aires protégées jouent un rôle important dans l'économie locale. Le défi consiste } \\
\text { à maintenir la qualité de la destination protégée afin que les aires locales bénéficient } \\
\text { toujours de l'utilisation. }\end{array}$ \\
\hline \multicolumn{2}{|l|}{ Aspects opérationnels } \\
\hline Qualité du site & $\begin{array}{l}\text { Des destinations propres, bien conçues, sans déchets, sans mauvaises herbes, } \\
\text { bien entretenues, non vandalisées et sûres font partie intégrante des aires protégées } \\
\text { accueillant des visiteurs. Cela nécessite un travail et des investissements constants de la } \\
\text { part des organisations chargées des aires protégées. }\end{array}$ \\
\hline Information pour les visiteurs & $\begin{array}{l}\text { Les informations de base pour les visiteurs avant leur arrivée dans une aire protégée, les } \\
\text { informations pendant leur visite et les informations après leur visite sont des investissements } \\
\text { importants. Il peut s'agir de renseignements sur les hébergements pour les chercheurs } \\
\text { invités, de cartes d'information pour les randonneurs, de renseignements sur les sites } \\
\text { d'observation de la faune pour les amateurs de nature, de panneaux d'emplacement des } \\
\text { coupe-feux pour les membres des brigades bénévoles, ou de toute une gamme d'autres } \\
\text { informations. L'information peut être présentée sur toute forme de supports. }\end{array}$ \\
\hline $\begin{array}{l}\text { Informations sur les } \\
\text { visiteurs }\end{array}$ & $\begin{array}{l}\text { Les données de base sur l'utilisation faites par les visiteurs sont essentielles pour la } \\
\text { gestion. II peut s'agir de données de base sur la présence et l'absence de visiteurs, de } \\
\text { contributions sur les heures de bénévolat, de commentaires sur le service à la clientèle, } \\
\text { d'attitudes des visiteurs et autres données. }\end{array}$ \\
\hline
\end{tabular}




\begin{tabular}{|c|c|}
\hline Exigences de quarantaine & $\begin{array}{l}\text { Des exigences strictes en matière de quarantaine peuvent être requises pour de } \\
\text { nombreuses aires protégées, en particulier celles de catégorie la. Cela aidera à éviter la } \\
\text { propagation d'agents pathogènes, de mauvaises herbes et d'animaux nuisibles dans les } \\
\text { aires protégées. }\end{array}$ \\
\hline Accès & $\begin{array}{l}\text { Toute une gamme d'accès peut être disponible dans les aires protégées. Typiquement, } \\
\text { ceux-ci seront soigneusement planifiés. L'accès peut se faire à pied, avec des animaux } \\
\text { de bât, par véhicule, par avion, par bateaux et véhicules submersibles, ainsi que par toute } \\
\text { une gamme de structures telles que chemins, passerelles, routes, tunnels et ponts. }\end{array}$ \\
\hline Installations & $\begin{array}{l}\text { Toute une gamme d'installations récréatives appropriées pour une aire protégée, et guidées } \\
\text { par un cadre de planification, peut être fournie. Typiquement, elles seront discrètes, et } \\
\text { souvent, elles refléteront l'environnement culturel et social du site. De nombreuses aires } \\
\text { protégées (ou zones à l'intérieur de celles-ci, comme les zones de nature sauvage) } \\
\text { conserveront des espaces sans aucune installation comme base de diversification des options } \\
\text { de loisirs. }\end{array}$ \\
\hline Personnel de soutien & $\begin{array}{l}\text { Des agents d'entrée, d'information, de terrain et des rangers bien informés, formés et en } \\
\text { uniforme fourniront des conseils et des informations inestimables qui aideront les visiteurs } \\
\text { à profiter de leur séjour dans une aire protégée. L'apprentissage des valeurs naturelles et } \\
\text { culturelles d'un territoire est un élément clé de l'écotourisme, très apprécié par ces visiteurs. }\end{array}$ \\
\hline Jouissance paisible & $\begin{array}{l}\text { L'accent étant mis sur la conservation de la biodiversité et la nature, on s'attend à ce } \\
\text { que les visiteurs des aires protégées puissent participer et profiter d'un environnement } \\
\text { respectueux de la nature. Les gestionnaires doivent être sensibles aux impacts sur le } \\
\text { plaisir des visiteurs, notamment la pollution de l'air et le bruit. }\end{array}$ \\
\hline Sécurité & $\begin{array}{l}\text { La sécurité des visiteurs est primordiale, et la vigilance obligatoire. On s'attend à ce que } \\
\text { les aires protégées effectuent des évaluations de la gestion des risques, afin de s'assurer } \\
\text { que leur personnel soit adéquatement formé pour faire face aux incidents de sécurité, et } \\
\text { que l'équipement ou le soutien nécessaire soit disponible, entretenu et prêt à l'emploi. }\end{array}$ \\
\hline Toilettes & $\begin{array}{l}\text { Des toilettes sont généralement nécessaires dans les aires protégées. Celles-ci } \\
\text { peuvent varier dans leur sophistication, mais elles doivent toujours être propres et bien } \\
\text { entretenues. }\end{array}$ \\
\hline \multicolumn{2}{|l|}{ Administration } \\
\hline Gestion des revenus & $\begin{array}{l}\text { La gestion des revenus, comme la perception de droits d'entrée ou de camping, } \\
\text { nécessitera la gestion d'argent et autres moyens de paiement, et entraînera des } \\
\text { exigences en matière de sécurité informatique et d'audit. }\end{array}$ \\
\hline Gestion de l'hébergement & $\begin{array}{l}\text { Un hébergement peut être prévu pour les touristes, les chercheurs invités et } \\
\text { les travailleurs des aires protégées. La gestion de l'hébergement comporte des } \\
\text { responsabilités en matière de réservation, de gestion des revenus, de nettoyage, de } \\
\text { service, d'entretien et de sécurité. }\end{array}$ \\
\hline Aliments et boissons & $\begin{array}{l}\text { Des restaurants et des installations de pique-nique peuvent être fournis, soit par } \\
\text { l'administration, soit par un concessionnaire ou un bailleur. Ces derniers peuvent générer } \\
\text { un loyer pour les administrateurs d'aires protégées, et fournir des possibilités d'emplois } \\
\text { locaux et d'approvisionnement. }\end{array}$ \\
\hline $\begin{array}{l}\text { Installations de vente au } \\
\text { détail }\end{array}$ & $\begin{array}{l}\text { Des boutiques vendant de l'artisanat, des cadeaux, des cartes, des guides, du matériel } \\
\text { d'observation de la faune et des aliments peuvent être exploitées dans les aires } \\
\text { protégées. Ces installations nécessiteront des services de soutien, notamment des } \\
\text { services publics, ainsi que des inspections sanitaires et de sécurité. }\end{array}$ \\
\hline
\end{tabular}

\section{Gestion du tourisme}

La gestion active du tourisme dans les aires protégées est essentielle pour que les générations futures puissent profiter des ressources naturelles et culturelles qu'elles protègent. Il est important de connaître l'industrie du tourisme et les intérêts et comportements des visiteurs, afin de mieux planifier les installations et les activités au sein des aires protégées, et définir les bonnes stratégies de gestion. De même, il est essentiel de comprendre la portée, le type et l'intensité des impacts du tourisme, et les façons de les éviter, minimiser et atténuer.

La gestion du tourisme dans les aires protégées est cruciale, car le tourisme naturel ne peut être durable que si les biens naturels et culturels sont conservés. Il existe de nombreux exemples, à travers le monde, de la façon dont le tourisme peut être bénéfique en fournissant une motivation et un soutien pour la conservation de l'environnement. En effet, sans l'incitation financière à la conservation découlant du tourisme, de nombreux organismes du secteur public 
accorderaient probablement moins d'attention à la protection de l'environnement naturel (Swarbroke, 1988).

Le principal risque du tourisme naturel est quil menace également de détruire les ressources dont il dépend. Par conséquent, les impacts des visites sur ces ressources doivent être soigneusement gérés, dirigés et atténués, et la question clé est de déterminer quels impacts sont acceptables (Eagles et al., 2002 ; Newsome et al., 2002). Il est important de bien connaître l'industrie du tourisme et les intérêts et comportements de ces visiteurs, ainsi que d'autres visiteurs, afin de planifier le tourisme dans les aires protégées et identifier les bonnes stratégies de gestion.

\section{Définition du tourisme}

L'Organisation mondiale du tourisme des Nations unies (OMT, 2014a) fournit les définitions suivantes.

- Voyages/tourisme : les voyages font référence à l'activité des voyageurs. Un voyageur est une personne qui se déplace entre différents endroits géographiques, quel que soit la fin et la durée de ce déplacement. Le visiteur est un type particulier de voyageur et, par conséquent, le tourisme est un sous-ensemble des voyages.

- Touriste : un visiteur (domestique, entrant ou sortant) est classé comme touriste (ou visiteur restant au moins une nuit) si son voyage comprend une nuitée.

- Visiteur : un visiteur est un voyageur se rendant dans une destination principale en dehors de son environnement habituel, pour une durée inférieure à un an, à une fin principale (affaires, loisirs ou autre fin personnelle) autre que pour être employé par une entité résidente dans le pays ou le lieu visité. Un visiteur (domestique, entrant ou sortant) est classé comme touriste (ou visiteur restant au moins une nuit) si son voyage comprend une nuitée, ou comme visiteur d'un jour (ou excursionniste) si ce n'est pas le cas.

En ce qui concerne les aires protégées, dans ce chapitre, nous utilisons une définition plus précise dans laquelle un touriste fait référence à quelqu'un qui voyage depuis sa résidence habituelle et reste au moins une nuit à des fins de loisirs ou pour le plaisir et les activités connexes, et utilise les industries et services visant à satisfaire les besoins des touristes (Worboys et al., 2005).

\section{Tourisme durable}

L'un des résultats du Sommet de Rio de 1992 a été un plan d'action global appelé Agenda 21. En ce qui concerne le tourisme, l'Agenda 21 a encouragé la formulation de programmes de tourisme respectueux de l'environnement et tenant compte des cultures, en tant que stratégie de développement durable (Nations unies, 1992). Les Nations unies ont souligné la nécessité d'une approche équilibrée du développement durable, et ont suggéré que le développement économique, le développement social et la protection de l'environnement sont trois composantes du développement durable, interdépendantes et se renforçant mutuellement (ONU, 1997). Elkington (1997) a qualifié cette poursuite simultanée de la prospérité économique, de la qualité de l'environnement et de l'équité sociale de " triple résultat » du développement durable. En tant que tel, le tourisme durable est défini comme " un tourisme tenant pleinement compte de ses impacts économiques, sociaux et environnementaux actuels et futurs, en répondant aux besoins des visiteurs, de l'industrie, de l'environnement et des communautés d'accueil » (PNUE et OMT, 2005:11-12).

\section{Tourisme socialement durable dans les aires protégées}

Une utilisation socialement durable peut également être plus sensible dans les aires protégées, surtout lorsqu'il existe un risque d'impact sur les communautés à l'intérieur des aires protégées, ou lorsque la sur-fréquentation est susceptible d'entraîner une expérience moins satisfaisante pour les visiteurs. Une attention particulière doit être accordée aux communautés d'accueil, comme dans les sites du Patrimoine mondial, dans le but de conserver l'intégrité culturelle de ces communautés.

\section{Tourisme financièrement durable dans les aires protégées}

L'importance de maintenir les recettes touristiques pour une aire protégée individuelle et pour une organisation chargée des aires protégées aidera idéalement à soutenir un service à la clientèle de qualité et des destinations sûres et propres. Les gestionnaires d'aires protégées devront être sensibles aux besoins commerciaux. Par exemple, le calendrier d'opérations de gestion telles que le brûlage, la lutte contre les animaux nuisibles, la lutte contre les mauvaises herbes et les tâches d'entretien pourra être planifié de façon à éviter les expériences négatives pour les visiteurs.

\section{Tourisme écologiquement durable dans les aires protégées}

Certaines interprétations d'une " utilisation écologiquement durable " mettent l'accent sur des considérations telles que la qualité de l'air, la qualité de l'eau, l'élimination des déchets et la consommation d'énergie. Une " utilisation écologiquement durable " met l'accent sur les écosystèmes et la biodiversité (CoA, 1991). Le tourisme dans les aires protégées doit être géré pour des résultats durables d'un point de vue environnemental et écologique. La 
Convention du patrimoine mondial et les Directives opérationnelles associées (UNESCO, 2011) prescrivent une utilisation écologiquement durable des sites naturels du Patrimoine mondial, afin de protéger les valeurs universelles exceptionnelles. La Directive opérationnelle 119 indique que les sites du Patrimoine mondial peuvent soutenir une utilisation écologiquement durable, à condition que cette utilisation n'ait pas d'impact négatif sur les valeurs universelles exceptionnelles (UNESCO, 2011). Beaucoup de ces sites du Patrimoine mondial sont des aires protégées.

La contribution de la gestion des aires protégées au tourisme écologiquement durable (ci-après dénommé tourisme durable) peut inclure :

- conseiller les visiteurs sur les soins durables spéciaux mis en œuvre dans l'aire protégée et les informer de comment ils contribuent à la gestion durable ;

- offrir aux visiteurs des options spéciales d'utilisation à faible impact, comme par exemple, aider les chercheurs à recueillir des données dans les aires protégées ;

- minimiser les impacts sur les destinations naturelles en planifiant les options de loisirs, en déterminant la nature des installations à fournir (comme l'absence d'installations à certains endroits), et en établissant des limites d'utilisation des sites par les visiteurs dans la planification ;

- intégrer toutes les installations aux contextes environnementaux et sociaux de l'aire protégée et, le cas échéant, maximiser l'efficacité énergétique et l'utilisation de sources d'énergie renouvelables grâce à une bonne conception et une planification efficace ;

- minimiser les impacts sur la flore et la faune autochtone par la recherche, le suivi et la gestion adaptative de l'utilisation par les visiteurs, ainsi que par des limites d'utilisation ;

- réduire au minimum la consommation d'énergie contribuant aux émissions de gaz à effet de serre ;

- minimiser, réutiliser et recycler les déchets solides et liquides ;

- minimiser la consommation de ressources en eau douce ;

- accorder une préférence aux opérateurs touristiques possédant des qualifications appropriées et reconnues de l'industrie du tourisme durable (telles qu'une écocertification de l'industrie ou des récompenses pour l'excellence en matière de gestion environnementale) dans les appel d'offres pour les opportunités touristiques autorisées ;

- offrir des possibilités économiques aux communautés et aux entreprises locales, y compris en ce qui concerne la propriété des entreprises touristiques, la fourniture de produits et de services à l'aire protégée et à ses visiteurs, et les emplois dans l'aire protégée, conformément au plan de gestion de l'aire protégée ;

- pratiquer une commercialisation sensible des attractions culturelles, en particulier celles intéressant à la fois les touristes et les résidents.

Les aires protégées constituent des destinations privilégiées pour des millions de personnes dans le monde entier, et d'un grand intérêt pour l'industrie du tourisme. Pour de nombreux opérateurs touristiques, elles représentent des destinations de choix permettant d'assurer des revenus et de réaliser des bénéfices pour les actionnaires. Les bénéfices sont l'objectif principal, la destination étant normalement une source de revenu. En l'absence de lignes directrices claires en matière de gestion, l'accès légal à une aire protégée par le biais d'un bail ou d'une licence touristique peut, au fil du temps, entraîner des développements commerciaux progressifs. Des décisions commerciales conscientes, stratégiques et progressives peuvent transformer un ancien site naturel protégé en un site urbanisé (figure 23.1). Cette sur-commercialisation des terres et de l'eau dans les aires protégées de catégorie II, par exemple, crée des défis dans de nombreuses régions du monde (Dudley, 2008). La réponse de gestion consiste à s'assurer que les baux ou permis initiaux soient rigoureux et aident à protéger la destination naturelle à long terme.

Le modèle de Butler du cycle de vie des produits touristiques est une façon d'envisager les destinations que constituent les aires protégées au fil du temps (Butler, 1980). Butler a conceptualisé un cycle de vie des produits touristiques dans lequel les produits passent par diverses étapes au cours de leur évolution, y compris le développement, la consolidation, la stagnation et finalement un déclin (figure 23.2). La pertinence du cycle de vie des destinations pour les aires protégées réside dans le développement de destinations et de produits touristiques durables. Pour cela, un objectif doit être défini, ce qui consiste à éviter les phases potentielles de stagnation et de déclin du cycle de vie en mettant l'accent sur une utilisation stable du tourisme d'un point de vue économique, environnemental, social et culturel.

\section{Types d'opérateurs touristiques}

Travailler avec les opérateurs touristiques dans les aires protégées est un élément essentiel pour atteindre des résultats touristiques durables. Chaque exploitation touristique d'une aire protégée est différente, et bien que toutes les exploitations respectent généralement les exigences de leur bail ou de leur licence, l'expérience en matière de gestion des aires protégées a montré que les exploitants envisagent le statut de protection de la destination touristique de différentes façons. Trois paradigmes d'approches des opérateurs touristiques à 


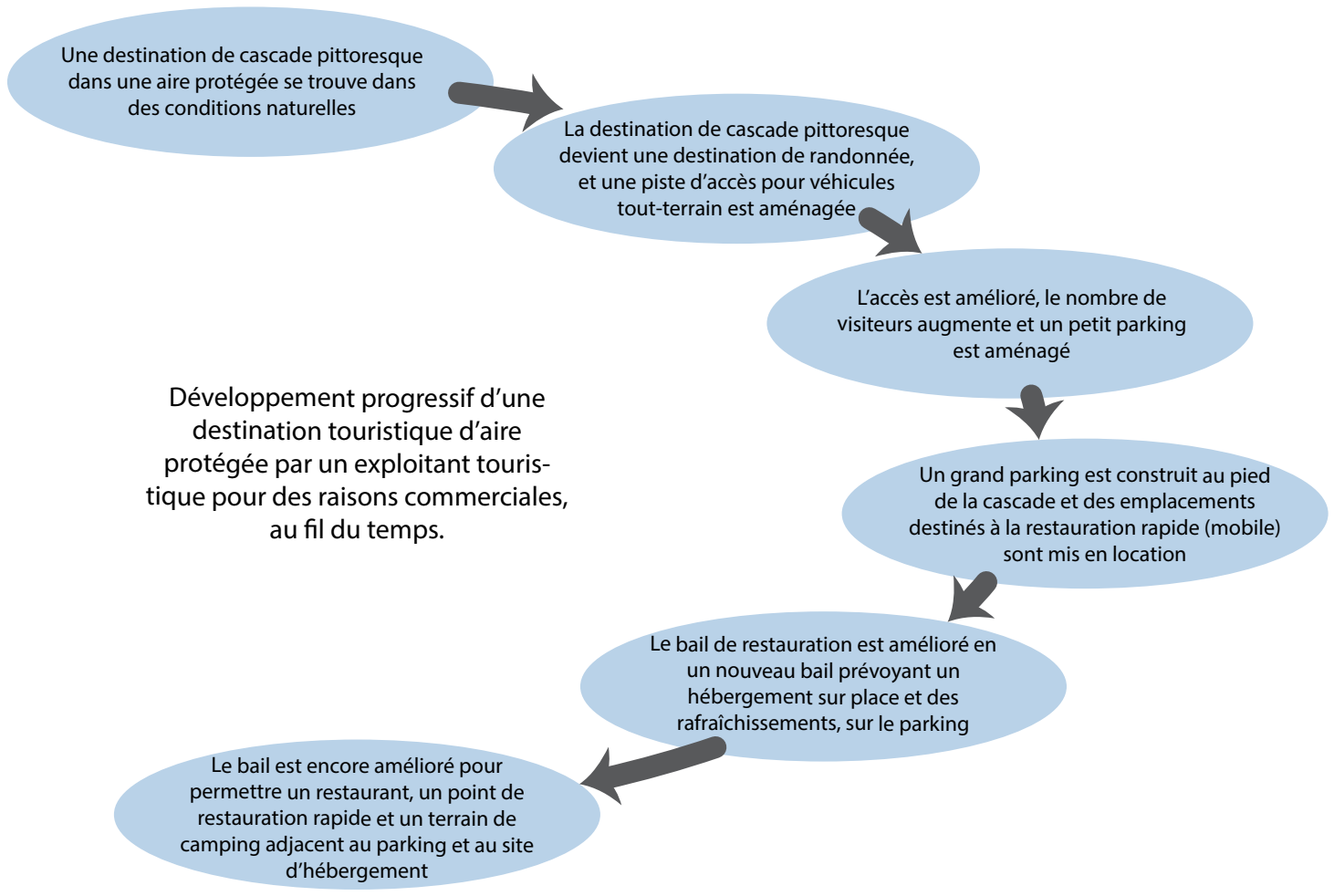

Figure 23.1 Illustration de développements progressifs, pilotés par les opérateurs touristiques dans les aires protégées, pour une attraction hypothétique d'une cascade

l'égard des aires protégées ont été reconnus et sont décrits ici (adapté de Worboys et al., 2005). La compréhension de ces différences est particulièrement importante pour les gestionnaires d'aires protégées susceptibles de négocier des accords juridiques avec les exploitants touristiques.

\section{Opération d'écotourisme}

Une opération d'écotourisme dans une aire protégée :

- dispose d'une autorisation d'exploitation ;

- fournit des services de base tels que l'hébergement, l'accès, le transport et la nourriture ;

- fonctionne sur une base commerciale, bien que certains bénéfices puissent être reversés aux aires protégées et communautés locales ;

- possède une politique d'entreprise affirmant un engagement pour l'environnement, la société, la culture et l'économie locale ;

- possède les qualifications appropriées d'industrie (ou autre) de tourisme durable ;

- possède une vision pro-environnement ;

- fournit une éducation environnementale de haute qualité aux visiteurs, ainsi qu'aux résidents locaux ;

- emploie la population locale et achète des produits et services locaux pour soutenir l'économie locale ;

- investit dans l'amélioration de la gestion environnementale ;
- travaille en étroite collaboration avec les gestionnaires pour aider à préserver l'aire protégée.

\section{Activités touristiques courantes}

Généralement, une opération touristique courante dans une aire protégée :

- dispose d'une autorisation d'exploitation ;

- fournit des services de base tels que l'hébergement, l'accès, le transport et la nourriture ;

- se comporte de façon professionnelle dans ses relations de travail avec l'organisation chargée des aires protégées ;

- entreprend une opération «à but lucratif »;

- fournit des informations de base visant à soutenir les visiteurs ;

- n’est pas nécessairement pro-aire protégée ou proenvironnement ;

- peut apporter une contribution positive occasionnelle à l'aire protégée ;

- ne dispose pas de personnel permanent possédant des qualifications environnementales.

\section{Exploitation touristique axée sur le développement}

Une exploitation touristique axée sur le développement dans une aire protégée : 


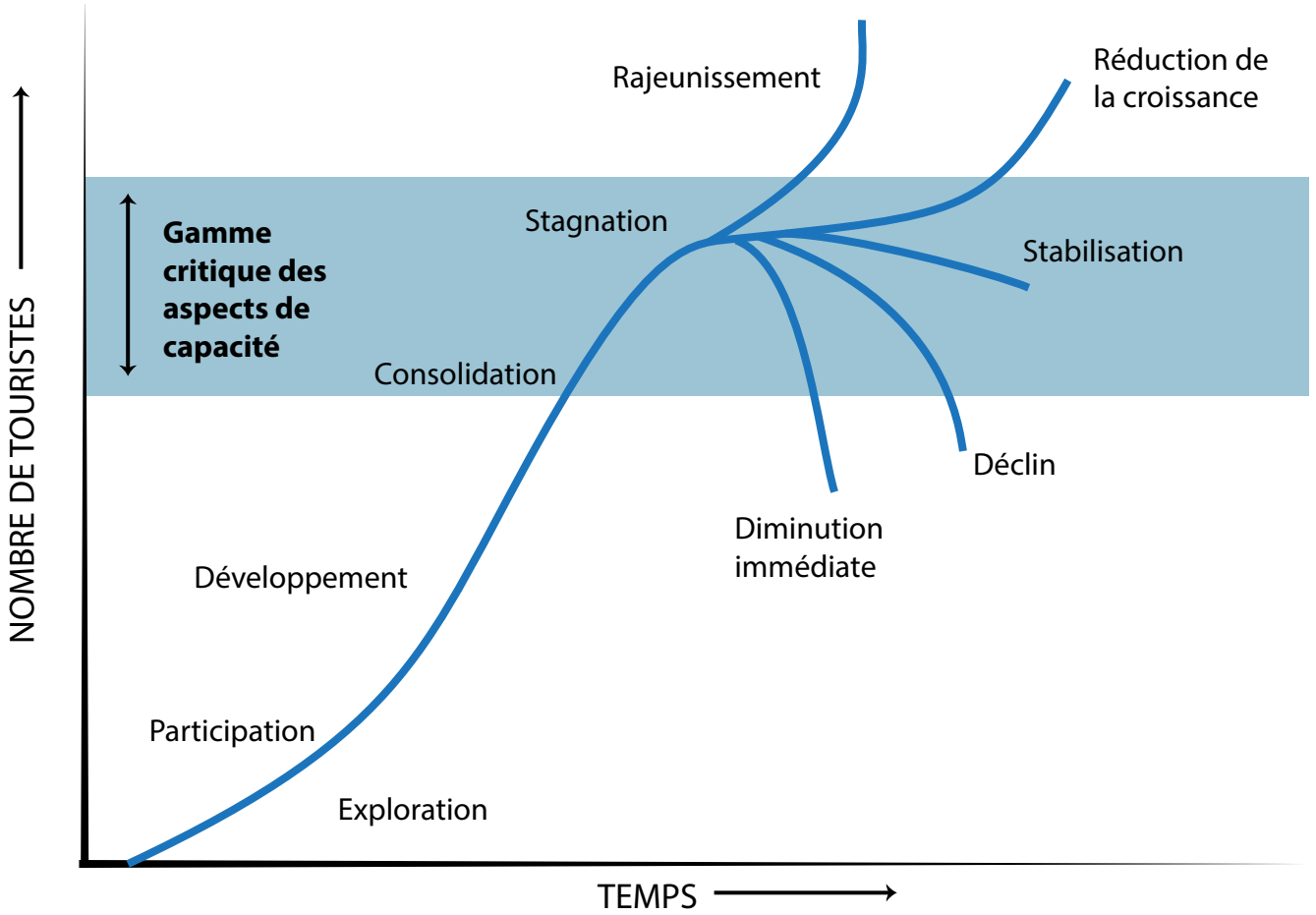

Figure 23.2 Cycle de vie des destinations touristiques de Butler Source : Adapté de Butler (1980)

- dispose d'un bail ou d'une licence d'exploitation ;

- fournit des services de base tels que l'hébergement, l'accès, le transport et la nourriture ;

- possède une approche idéologique pro-commerciale et axée sur les profits ;

- fournit des paiements de location ou de licence et entreprend des travaux obligatoires (légaux) ;

- utilise des soutiens juridiques et politiques de haut niveau pour faciliter les décisions pro-commerciales dans une aire protégée ;

- considère les aires protégées comme une propriété de destination à des fins commerciales uniquement ;

- ne présente qu'une faible tolérance pour les considérations de gestion environnementale et les demandes de mesures de conservation ;

- offre des emplois liés au tourisme ;

- fournit un service efficace pour les visiteurs ;

- ne dispose pas de personnel permanent disposant d'une expertise en gestion de l'environnement.

Les opérations touristiques (prestations de service) dans les aires protégées sont généralement achetées et vendues au fil du temps. Lorsqu'ils négocient des baux à long terme pour des activités touristiques, les gestionnaires d'aires protégées devront toujours négocier les modalités comme s'ils avaient affaire à une exploitation touristique axée sur le développement.

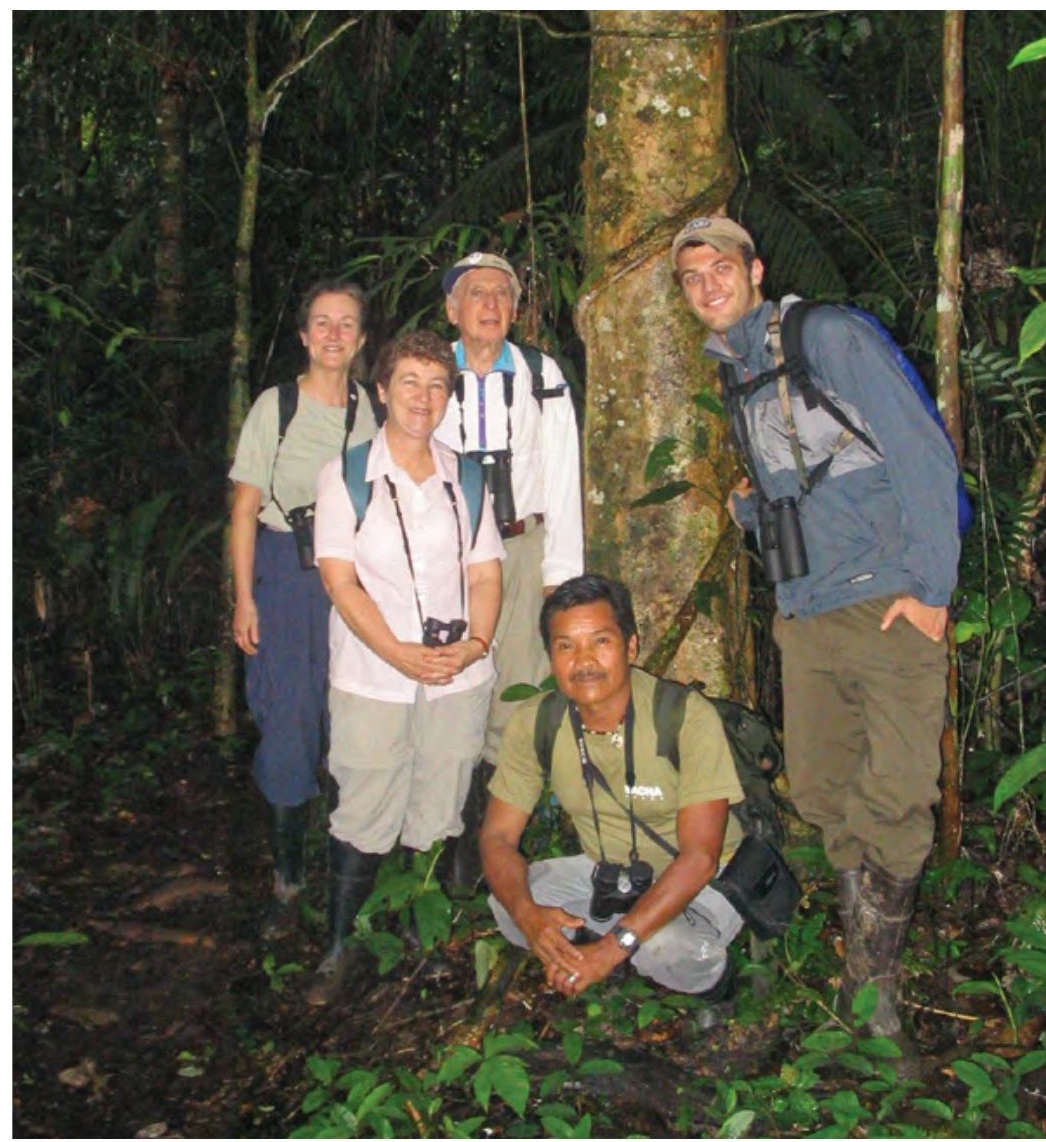

Écotouristes et guides lors d'une visite guidée de la forêt tropicale, cours supérieur de l'Amazone, Équateur

Source : Graeme L. Worboys 


\section{Nombre et types de touristes}

L'OMT prévoit une croissance annuelle des arrivées de touristes internationaux de $4 \%$ par an entre 2013 et 2020 . En 2013, il y a eu 1,087 milliard d'arrivées internationales (OMT, 2014b). Cette prévision de croissance aura des conséquences directes pour les gestionnaires d'aires protégées du monde entier, qui devront gérer activement le tourisme dans les aires protégées.

Il existe un large éventail de secteurs touristiques liés aux aires protégées, notamment le tourisme de masse, le tourisme de nature, le tourisme d'aventure, l'écotourisme, le tourisme de conservation, le tourisme culturel, le tourisme bénévole, le tourisme éducatif ou le tourisme religieux.

Le tourisme de masse est synonyme d'un grand nombre de visiteurs entreprenant des activités, avec une différenciation limitée et une immersion réduite dans l'authenticité. Les visiteurs « se déconnectent " généralement et deviennent ambivalents à leur environnement et à toutes les attentes de l'hôte. Par conséquent, le tourisme de masse est moins susceptible d'atteindre les objectifs de gestion des aires protégées que certains des secteurs touristiques de niche décrits ci-après.

Le tourisme de nature est décrit comme toute forme de tourisme " utilisant les ressources naturelles sous une forme sauvage ou non développée, y compris les espèces, les habitats, les paysages et les éléments d'eau douce et salée. Le tourisme de nature est un voyage dans le but de profiter de sites naturels non développés ou de la faune sauvage " (Goodwin, 1996:15).

Le tourisme d'aventure est une forme de tourisme de nature intégrant un élément de risque, des niveaux plus élevés d'effort physique, et souvent, un besoin de compétences spécialisées, comme par exemple, le rafting dans le parc national du Grand Canyon, aux États-Unis (Buckley, 2006).

L'écotourisme est un sous-ensemble du tourisme de nature avec une éthique plus forte. Il a été défini par la Société d'écotourisme comme un voyage responsable dans les sites naturels, qui préserve l'environnement et améliore le bienêtre des populations locales (TIES, 1990), et par Frangialli (2001:4) comme « toute forme de tourisme dans laquelle la motivation principale des touristes est l'observation et l'appréciation de la nature, contribuant à la conservation de l'environnement naturel et du patrimoine culturel, et ne générant qu’un impact minimal ».

Le tourisme de conservation reprend une partie de l'éthique de l'écotourisme mais va encore plus loin. Il a été défini comme un tourisme fonctionnant comme un outil de conservation, apportant une contribution positive nette et significative sur le plan écologique à la conservation efficace de la diversité biologique (Buckley, 2010). Le tourisme

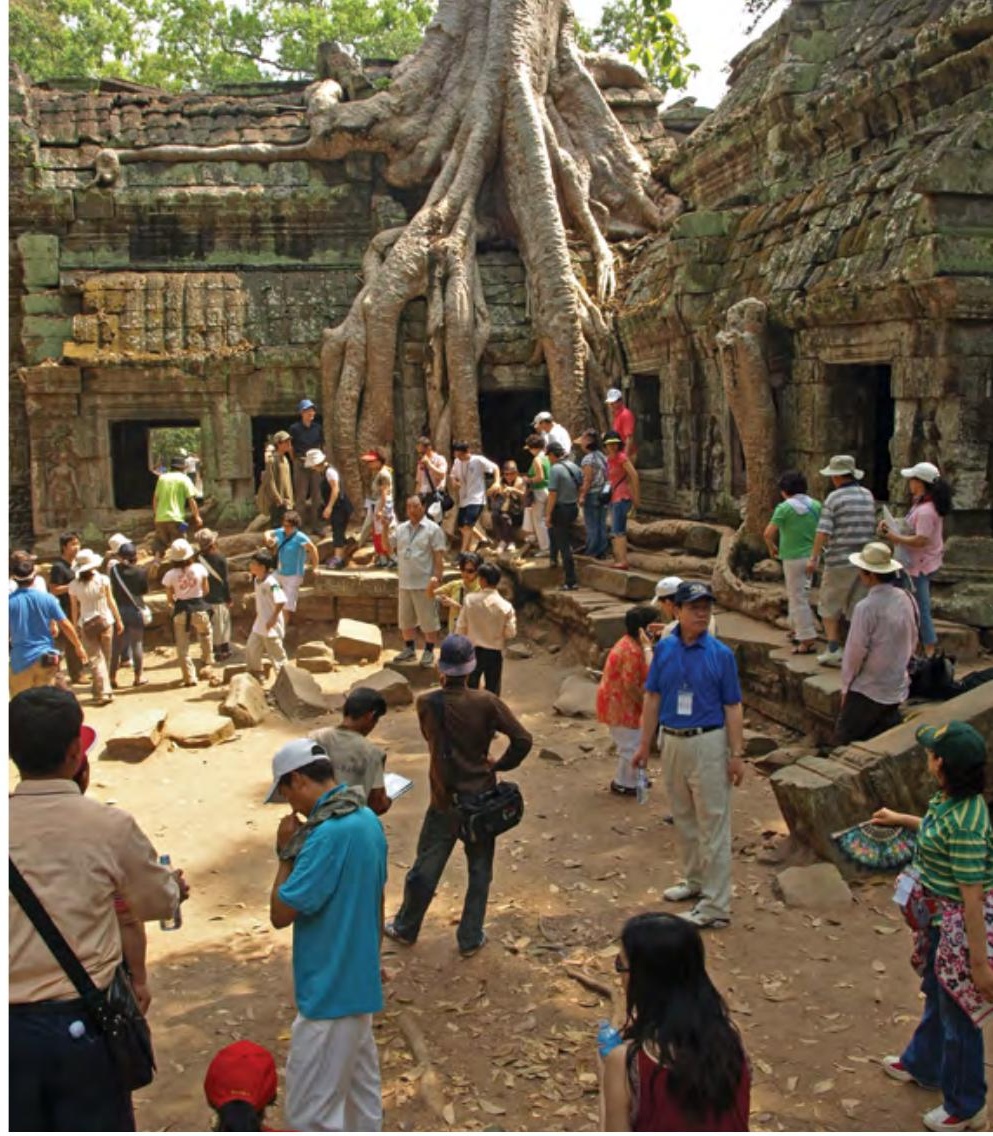

Visiteurs au temple de Ta Prohm, Angkor, Cambodge

Source : Graeme L. Worboys

de conservation implique le touriste dans une activité de conservation, ce qui constitue une partie ou la plupart de son expérience. Il peut être proposé par les voyagistes, les opérateurs d'hébergement et les opérateurs d'attraction. Lun des exemples les plus connus concerne les cas où des terres de grande importance pour la conservation et une utilisation historique comme le pâturage ou l'agriculture sont achetées, remises en état et gérées pour la conservation des aires protégées en tant que réserves de faune, en Afrique, ou de propriétés de l'Australian Wildlife Conservancy, en Australie.

Le tourisme culturel est un segment touristique qui se concentre sur la culture d'un pays, y compris l'histoire, l'art, l'architecture et la religion. Ses origines remontent, en partie, au « Grand tour » du continent européen de l'aristocratie aux XVIIe, XVIIIe et XIXe siècles (Chee et al., 1997). Il peut également inclure le tourisme dans les zones rurales et les aires protégées mettant en valeur le patrimoine culturel, tels que les sites d'art ancien, les bâtiments historiques et le patrimoine immatériel. Le patrimoine culturel immatériel regroupe " les pratiques, expressions, connaissances et compétences, ainsi que les objets et espaces culturels associés que les communautés et les individus reconnaissent comme faisant partie de leur patrimoine culturel » (OMT, 2012:2).

Tout type de vacances incluant un service volontaire à destination est considéré comme du tourisme bénévole. Le touriste ne reçoit aucun type de compensation financière pour les différents types de travaux qu'il entreprend, et dans de nombreux cas, doit même fournir une contribution financière. Les bénévoles de la réserve naturelle de Montague 
Island, en Nouvelle-Galles du Sud, par exemple, paient des frais pour aider au travail bénévole sur l'île (Pacey, 2013).

Le tourisme éducatif comprend les voyages permettant de participer à des expériences éducatives locales et à l'étranger, mais pas l'inscription à un programme d'études à l'étranger pour l'obtention de crédits d'études. De nombreuses organisations bénévoles guidées par une mission offrent des voyages d'apprentissage pour les groupes scolaires (à tous les niveaux d'éducation, et dans certains cas, pour les adultes), dans lesquels ceux-ci acquièrent une expérience pratique dans certains domaines culturels, scientifiques ou de développement communautaire, y compris les aires protégées. La réserve privée de la forêt tropicale de Monteverde, au Costa Rica, par exemple, se caractérise par un objectif éducatif majeur (TSC, 2014), tout comme la plupart des aires protégées de catégorie II.

Le tourisme religieux, ou tourisme de la foi, regroupe les individus voyageant à des fins de pèlerinage, de mission ou de loisirs, comme l'accès à des sites importants dans le parc national du Grand Himalaya, en Inde, pour des cérémonies religieuses importantes (Weaver et Lawton, 2002).

D'autres types de tourisme sont susceptibles d'impliquer des aires protégées privées et des aires protégées de catégorie $V$ et VI en particulier, comme le tourisme rural, l'agrotourisme et le tourisme de consommation (où la faune ou les plantes sont collectées, chassées ou pêchées selon une utilisation gérée et durable).

Les loisirs sont des activités volontairement entreprises principalement pour le plaisir et la satisfaction, pendant le temps libre, et sont une caractéristique habituelle des aires protégées (Worboys et al., 2005). Aux fins du présent chapitre, le terme tourisme désigne également les loisirs.

\section{Touristes domestiques et étrangers}

Selon l'OMT (2014a), le tourisme entrant comprend les activités d'un visiteur non-résident dans le pays de référence lors d'un voyage touristique entrant. Le tourisme intérieur comprend le tourisme domestique plus le tourisme entrant, englobant les activités des visiteurs résidents et nonrésidents dans le pays de référence dans le cadre de voyages touristiques nationaux ou internationaux. Le tourisme sortant comprend les activités d'un visiteur résident à l'extérieur du pays de référence, que ce soit dans le cadre d'un voyage touristique sortant ou d'un voyage de tourisme. Enfin, le tourisme international comprend le tourisme entrant et le tourisme sortant, y compris les activités des visiteurs résidents à l'extérieur du pays de référence, dans le cadre de voyages touristiques nationaux ou sortants, et les activités des visiteurs non-résidents dans le pays de référence lors de voyages touristiques entrants.

\section{Touristes d'un jour et de plus d'un jour}

Les touristes de plus d'un jour et les visiteurs d'un jour participeront à différents types d'activités dans les aires protégées, en fonction de leur disponibilité en temps et des installations ou produits offerts par la destination. Il est important de connaitre le nombre de visiteurs d'un jour et de plus d'un jour, afin d'aider à évaluer les types d'hébergement, d'infrastructures et de services devant être fournis à l'extérieur des aires protégées, et dans le cas des destinations d'un jour, dans les parcs.

\section{Visites organisées et voyageurs indépendants}

Les touristes peuvent faire partie de visites organisées ou voyager de façon indépendante. Les visiteurs potentiels d'une aire protégée pourront acheter un voyage organisé auprès d'un voyagiste local ou d'un agent de voyages, ou par l'intermédiaire de leur hôtel ou de leur centre de villégiature tout compris ou, de plus en plus, par internet. Les aires protégées offrent aux prestataires touristiques la possibilité d'ajouter de la valeur aux excursions qu'elles proposent, et pour de nombreux voyagistes spécialisés, les visites de sites de haute qualité reconnus à l'échelle mondiale peuvent représenter une proportion importante des ventes. Les visites de groupe organisés seront généralement dirigées par des voyagistes agréés, souvent responsables de transmettre clairement aux voyageurs des informations sur leurs droits et obligations lors de la visite d'une aire protégée.

Certains visiteurs peuvent voyager de façon libre et indépendante, après avoir pris leurs dispositions à partir $\mathrm{du}$ bouche à oreille, de recommandations des réseaux sociaux en ligne ou de suggestions d'un hôtel local, d'un guide, d'un bureau d'informations touristique et/ou de sites officiels. Dans certains cas, il peut être plus difficile de gérer les actions des touristes individuels que celles des visites organisées dans les aires protégées.

\section{Travailler avec l'industrie du tourisme}

\section{Contexte}

Le travail des gestionnaires d'aires protégées avec l'industrie touristique commence généralement par la compréhension des besoins, des attentes et des possibilités. Travailler ensemble exige une reconnaissance claire du fait que le tourisme dans les aires protégées doit être compatible avec les buts des aires protégées, y compris la primauté des objectifs de conservation et la reconnaissance des coûts et avantages associés au tourisme dans les aires protégées. Les coûts incluent la fourniture et l'entretien des infrastructures touristiques et les impacts environnementaux du tourisme (y compris les 
coûts de minimisation des impacts et de restauration des dommages une fois qu'ils se sont produits). Les avantages comprennent les résultats sociaux et économiques, par exemple, les emplois et l'approvisionnement locaux, et les bénéfices dérivés des services sociaux locaux.

\section{Besoins des opérateurs touristiques de la part des gestionnaires d'aires protégées}

L'industrie du tourisme a besoin de destinations touristiques sûres, fiables, propres, accessibles, bien gérées et conviviales pour ses clients. Elle a besoin que l'administration de ses baux et de ses permis soit ordonnée, et à long terme, afin que tout changement (par exemple, dans les frais) soit respecté. Les activités des aires protégées susceptibles d'avoir un impact sur le tourisme, comme les travaux routiers, les programmes de réduction des combustibles forestiers ou les programmes de lutte contre les animaux nuisibles et les mauvaises herbes, devront être entreprises, si possible, pendant les périodes de faible utilisation par les visiteurs. Ces courtoisies font partie d'un partenariat sain et positif avec les opérateurs touristiques. Au-delà de ces besoins clés, on trouve de nombreuses autres exigences connexes et de soutien, telles que la fourniture et le maintien d'infrastructures accessibles, des équipements de base pour que les visiteurs puissent profiter de l'aire protégée, telles que des abris et des commodités, et des informations et interprétations pertinentes et intéressantes sur l'aire protégée à l'intention des visiteurs.

\section{Besoins des gestionnaires d'aires protégées de la part des opérateurs touristiques}

Les gestionnaires d'aires protégées ont de multiples responsabilités et doivent se concentrer sur toute une gamme de questions. Ceci sera facilité si les opérateurs touristiques du parc peuvent aider à la gestion en :

- communiquant à leurs invités un message sur l'importance de l'aire protégée et le travail effectué dans les coulisses par les gestionnaires qui maintiennent le caractère spécial du site ;

- identifiant toute contribution spécifique des invités susceptible de protéger le site, par exemple, ne pas toucher les peintures rupestres ;

- identifiant comment leur entreprise contribue positivement à l'amélioration de la gestion de l'aire protégée ;

- respectant les demandes de protection de la réserve.

\section{Avantages d'un tourisme bien géré pour les aires protégées}

Un tourisme bien géré peut contribuer à la gestion des aires protégées par :

- l'amélioration du profil de l'aire protégée aux niveaux local, national et international ;

- le transport de visiteurs jusqu'à l'aire protégée, en particulier les personnes ayant besoin de services et d'installations pour faire ce voyage ;

- l'interprétation des valeurs et des enjeux de conservation et de gestion pour les visiteurs ;

- une justification économique pour la déclaration et la gestion de l'aire protégée (générer des dépenses de visiteurs, des emplois et des investissements dans l'aire protégée ou la communauté environnante) ;

- un soutien financier aux aires protégées par le paiement de redevances et de droits ;

- un soutien en ressources humaines par le biais d'activités de tourisme de conservation ;

- un soutien politique à la conservation de l'aire protégée, et les ressources nécessaires pour le faire efficacement.

\section{Planification de la collaboration avec l'industrie du tourisme}

Le large éventail d'entreprises de voyages et de tourisme, ainsi que de touristes, implique que les gestionnaires d'aires protégées devront envisager un éventail de stratégies pour collaborer avec l'industrie du tourisme. Il n'existe pas de modèle standard pour développer de telles relations, et chaque cas doit être considéré dans son contexte (UNEP, 2005). En raison de la manière dont l'industrie du tourisme est organisée, les voyagistes sortants (ou les entreprises touristiques internationales telles que les opérateurs de croisières) n'ont pas souvent de liens directs avec les aires protégées. Bien que les voyagistes entrants aient généralement quelques liens, les entreprises locales sont susceptibles de posséder les liens les plus étroits avec les aires protégées voisines (figure 23.3).

Les stratégies et activités de mise en relation des gestionnaires d'aires protégées avec l'industrie du tourisme seront également déterminées par la façon dont les visites d'une aire protégée spécifique seront organisées, et comment les touristes pourront connaître le site. Les trois scénarios suivants constituent un point de départ pour déterminer les stratégies les plus appropriées pour travailler avec l'industrie du tourisme (PNUE, 2005) :

1. Si les touristes viennent dans le cadre d'un forfait acheté à l'étranger, les connexions avec les voyagistes internationaux, d'abord en établissant des liens avec 


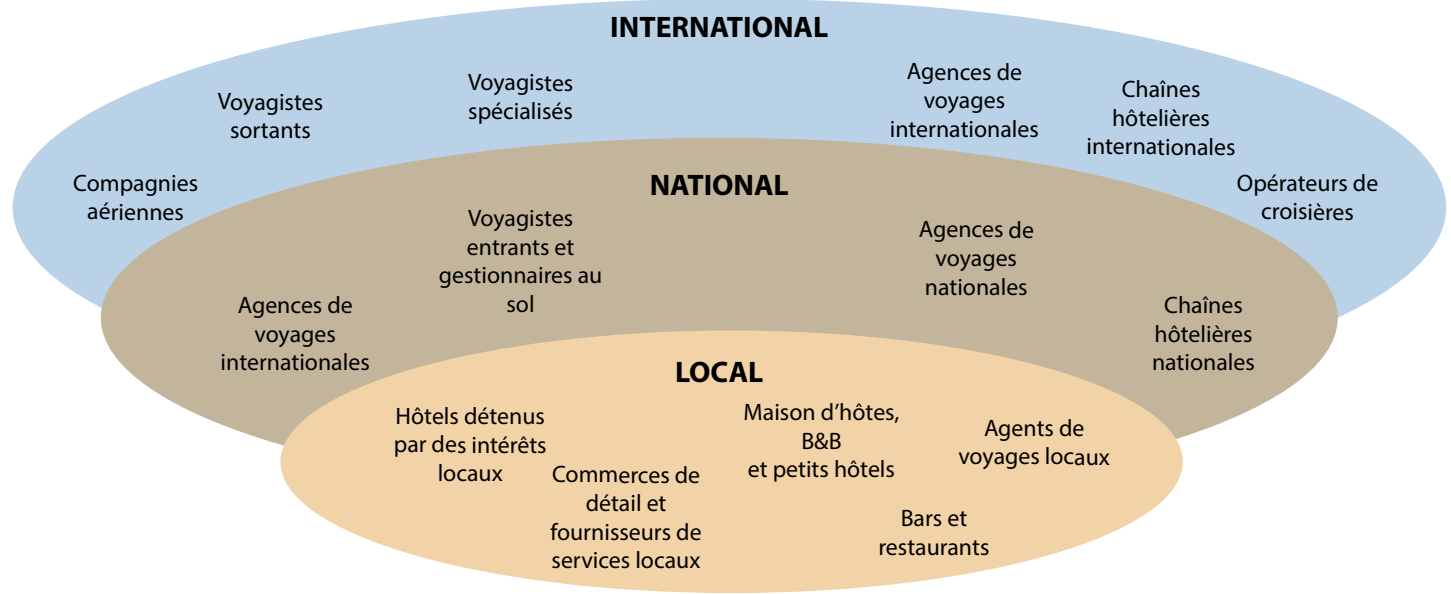

Figure 23.3 Échelles des entreprises touristiques

Source : Adapté de UNEP (2005)

les opérateurs locaux entrants que les entreprises internationales utilisent, sont susceptibles d'être importantes.

2. Si les voyageurs achètent leur voyage ou leurs visites sur place, les liens avec les voyagistes et les agents de voyages locaux seront plus appropriés.

3. Si les touristes organisent leur propre voyage, les liens avec les hôtels locaux, les bureaux d'information touristique, les centres d'accueil des visiteurs, les sites web, les réseaux sociaux et les forums web de voyageurs seront les plus importants.

Il est également important que les gestionnaires étudient s'ils souhaitent s'engager " activement " dans le tourisme, en créant et en gérant eux-mêmes des produits et services touristiques, ou s'impliquer plus " passivement " en accueillant des activités exploitées par d'autres (par exemple, en utilisant des concessions et en gérant des contrats d'externalisation).

\section{Baux et licences}

Un cadre structuré et clair pour le tourisme au sein d'une aire protégée aide à définir les attentes et crée un espace pour les opportunités. Au niveau le plus élémentaire, on trouve les outils contractuels juridiques qu'un gestionnaire utilisera pour approuver l'accès d'un opérateur touristique à l'aire protégée, par exemple, les concessions, permis, licences et baux. Ces contrats fixent les attentes pour l'exploitation et les frais requis. Ils ont une durée définie et peuvent être prolongés par simple paiement ou peuvent nécessiter des révisions et des mises à jour régulières.

\section{Politiques et plans en matière de tourisme}

À un niveau plus avancé, on trouve les politiques et plans touristiques pour les aires protégées. Ceux-ci font passer la gestion de réactive à proactive, en introduisant des approches stratégiques pour rendre le tourisme plus durable. Ils peuvent être intégrés dans les plans de gestion d'une aire protégée ou se présenter sous forme de documents autonomes.

Les politiques touristiques peuvent définir :

- la justification de l'autorisation du tourisme dans les aires protégées ;

- les types de tourisme et d'activités autorisés ;

- les éléments du tourisme durable, y compris la conservation et l'impact économique local ;

- les types de tourisme et d'activités préférés;

- les exigences contractuelles;

- la perception des droits.

Les plans touristiques peuvent définir :

- les visites actuelles et prévues;

- les profils de visiteurs actuels et les marchés cibles souhaités ;

- les impacts actuels du tourisme et les moyens de les minimiser ;

- l'amélioration des infrastructures et des services touristiques;

- l'amélioration de l'interprétation;

- un zonage destiné à différentes formes et niveaux de développement touristique ;

- les emplacements de nouveaux investissements, installations ou activités touristiques ;

- des idées pour de nouvelles expériences touristiques. 


\section{Revenus du tourisme}

De nombreux organismes de gestion des aires protégées n'ont pas les fonds nécessaires pour répondre adéquatement aux besoins et à la gestion du tourisme (Emerton et al., 2006a). Les fonds sont généralement plus importants dans les pays développés que dans les pays en développement, et souvent plus importants là où l'activité touristique et le développement sont concentrés. Le coût de la gestion de ces sites est cependant plus élevé, ce qui compense généralement les gains. En vertu du principe de l'utilisateur-payeur, les fonds nécessaires à la gestion du tourisme peuvent être recueillis auprès de sources directes et indirectes.

\section{Droits d'entrée}

Le revenu le plus commun du tourisme est un droit d'entrée direct permettant d'accéder à l'aire protégée (Font et al., 2004), bien que les frais liés aux activités permettent également de générer des revenus. Les aires protégées à forte concentration touristique peuvent générer entre 40 et $60 \%$ de leurs revenus à partir de frais d'utilisation (OMT, 1995; Emerton et al., 2006b).

Un défi majeur consiste à s'assurer que les fonds sont réinvestis dans la gestion des aires protégées. De nombreux gouvernements transferent les fonds collectés dans leur gestion centralisée des revenus et n'assimilent pas les redistributions au revenu initial, de sorte quau mieux, une aire protégée paie pour une autre, et dans le pire des cas, les recettes des aires protégées contribuent à des services pangouvernementaux indépendants, tels que la défense. D'autres gouvernements utilisent les droits pour réduire leur allocation traditionnelle à l'aire protégée, de sorte que si les droits de visite diminuent, la gestion devient considérablement sous-financée. Les organismes de parcs autorisés à gérer leurs propres fonds sont généralement plus autonomes, plus entreprenants et plus efficaces (Phillips,
2000 ; Lockwood et al., 2006). Une organisation chargée des aires protégée, le Service des parcs nationaux et de la faune sauvage de Nouvelle-Galles du Sud, en Australie, par exemple, a négocié une formule avec le gouvernement de Nouvelle-Galles du Sud selon laquelle l'organisation conserve les revenus collectés et n'est pas ouvertement pénalisée par ses recettes entrantes.

Le deuxième défi majeur de la collecte de droits d'entrée est de s'assurer que le coût de la collecte est nettement inférieur aux revenus générés. Il est souvent peu rentable de percevoir des frais dans les aires isolées, tandis que dans les aires présentant des variations saisonnières de fréquentation, il est souvent plus économique de facturer pendant la période de pointe et non en basse saison. Si la marge bénéficiaire est faible, il est difficile de démontrer où les revenus ont été investis, ce qui réduit le soutien des parties prenantes à la taxe.

Le troisième défi consiste à fixer des frais reflétant correctement les niveaux d'utilisation et les coûts de gestion subséquents. Un droit d'entrée forfaitaire n'est souvent pas considéré comme équitable, car certains visiteurs utilisent le site plus que d'autres, créent des impacts négatifs plus importants ou plus de demande sur la gestion. Des solutions alternatives à un droit d'entrée standard sont proposées dans le tableau 23.4.

Bien que plus complexes à gérer, des frais d'utilisation sont plus efficaces qu'un droit d'entrée, le prix payé étant mieux adapté à l'utilisation et à la gestion ultérieure.

\section{Frais des opérateurs}

Les entreprises touristiques opèrent à l'intérieur des aires protégées et gagnent de l'argent en utilisant les aires protégées. Les gestionnaires d'aires protégées ont donc le droit légitime de facturer l'exploitant pour leur utilisation du site. Certaines des façons dont des revenus peuvent

Tableau 23.4 Méthodes alternatives aux droits d'entrée

\begin{tabular}{|l|l|l|}
\hline Alternative & \multicolumn{2}{l}{ Exemple } \\
\hline $\begin{array}{l}\text { Facturer le temps } \\
\text { d'utilisation }\end{array}$ & $\begin{array}{l}\text { Définir un tarif journalier, majoré en cas de séjour de } \\
\text { plus d'un jour. }\end{array}$ & $\begin{array}{l}\text { Un parking facturé en fonction du temps } \\
\text { stationné. }\end{array}$ \\
\hline $\begin{array}{l}\text { Définir différents tarifs } \\
\text { pour utiliser différentes } \\
\text { zones }\end{array}$ & $\begin{array}{l}\text { Tarif plus élevé pour les zones de gestion coûteuses } \\
\text { et moins pour les zones à faible coût, ou plus pour } \\
\text { visiter ou utiliser des zones hautement fréquentées. }\end{array}$ & $\begin{array}{l}\text { Tarifs plus élevés pour le camping en } \\
\text { bord de mer que le camping intérieur. }\end{array}$ \\
\hline Frais d'utilisation & $\begin{array}{l}\text { Tarif plus élevé pour les activités nécessitant plus } \\
\text { d'infrastructures et de gestion. }\end{array}$ & $\begin{array}{l}\text { Tarif plus élevé pour une entrée de ski } \\
\text { que pour les visiteurs d'été. }\end{array}$ \\
\hline $\begin{array}{l}\text { Tarif plus élevé pour } \\
\text { ceux qui ont les } \\
\text { moyens de payer plus }\end{array}$ & $\begin{array}{l}\text { Tarif plus élevé pour les visiteurs internationaux, tarif } \\
\text { réduit pour les nationaux, entrée gratuite pour les } \\
\text { locaux. }\end{array}$ & $\begin{array}{l}\text { Tarif plus élevé pour les visiteurs } \\
\text { internationaux que pour les visiteurs } \\
\text { nationaux ou locaux. }\end{array}$ \\
\hline $\begin{array}{l}\text { Frais d'utilisation haute- } \\
\text { saison et basse-saison }\end{array}$ & $\begin{array}{l}\text { Droits d'entrée plus élevés pendant la période la } \\
\text { plus populaire de l'année. }\end{array}$ & $\begin{array}{l}\text { Tarifs plus élevés pendant les périodes } \\
\text { de vacances, ou pour les skieurs, } \\
\text { pendant les mois d'hiver. }\end{array}$ \\
\hline
\end{tabular}


Tableau 23.5 Méthodes de collecte de revenus de l'industrie touristique

\begin{tabular}{|c|c|c|}
\hline $\begin{array}{l}\text { Frais pour } \\
\text { l'opérateur }\end{array}$ & Signification & Secteur touristique idéal \\
\hline Frais de permis & $\begin{array}{l}\text { Une petite redevance est prélevée chaque } \\
\text { année ou selon les besoins. }\end{array}$ & $\begin{array}{l}\text { Pour les opérations irrégulières, telles que les } \\
\text { événements et les manifestations, et les très } \\
\text { petites entreprises et activités saisonnières. }\end{array}$ \\
\hline $\begin{array}{l}\text { Concessions et droits } \\
\text { de licence }\end{array}$ & $\begin{array}{l}\text { Une redevance modeste est prélevée sur } \\
\text { une base annuelle dans le cadre d'un permis } \\
\text { qui documente la façon dont l'exploitation } \\
\text { peut avoir lieu dans l'aire protégée. Souvent, } \\
\text { cela peut être envisagé dans le cadre de } \\
\text { dispositions d'exclusivité, offrant ainsi des } \\
\text { possibilités de rendements plus élevés. }\end{array}$ & $\begin{array}{l}\text { Pour les petites et moyennes opérations } \\
\text { régulières, telles que les transports et les } \\
\text { voyagistes. }\end{array}$ \\
\hline Bail de location & $\begin{array}{l}\text { Un montant fixe de loyer est facturé sur } \\
\text { une base mensuelle ou trimestrielle, } \\
\text { généralement augmenté avec l'inflation. } \\
\text { Souvent, cela peut être envisagé dans le } \\
\text { cadre de dispositions d'exclusivité, offrant } \\
\text { ainsi des possibilités de locations plus } \\
\text { élevées. }\end{array}$ & $\begin{array}{l}\text { Pour les entreprises dont les opérations } \\
\text { fixes génèrent des revenus importants et } \\
\text { nécessitent un soutien de gestion important, } \\
\text { tels que hébergement (hôtel, gîte, camp de } \\
\text { tentes), restauration et boissons (restaurant, } \\
\text { centre de réception, café), attraction (parc } \\
\text { d'aventure, téléphérique) et transport fixe } \\
\text { majeur (aéroport, port, marina et trains). }\end{array}$ \\
\hline $\begin{array}{l}\text { Frais de chiffre } \\
\text { d'affaires / excédent }\end{array}$ & $\begin{array}{l}\text { Lorsque le chiffre d'affaires est supérieur à } \\
\text { un montant convenu, l'exploitant verse une } \\
\text { partie du chiffre d'affaires supplémentaire au } \\
\text { gestionnaire de l'aire protégée. }\end{array}$ & $\begin{array}{l}\text { Pour les entreprises présentant un bon } \\
\text { potentiel de croissance, en particulier par le } \\
\text { biais de coopérations avec la gestion des aires } \\
\text { protégées. }\end{array}$ \\
\hline $\begin{array}{l}\text { Accords de services } \\
\text { partagés }\end{array}$ & $\begin{array}{l}\text { L'exploitant accepte d'assumer des rôles } \\
\text { qui seraient autrement assumés par le } \\
\text { gestionnaire de l'aire protégée, en échange } \\
\text { de frais financiers moins élevés. }\end{array}$ & $\begin{array}{l}\text { Pour les entreprises susceptibles de fournir } \\
\text { des services de manière plus rentable grâce à } \\
\text { des rôles d'employés multitâches, le partage } \\
\text { des infrastructures et des équipements, par } \\
\text { exemple, l'entretien des routes et des sentiers, } \\
\text { le nettoyage et l'entretien des équipements, } \\
\text { la fourniture d'interprétation et les activités de } \\
\text { conservation de base. }\end{array}$ \\
\hline
\end{tabular}

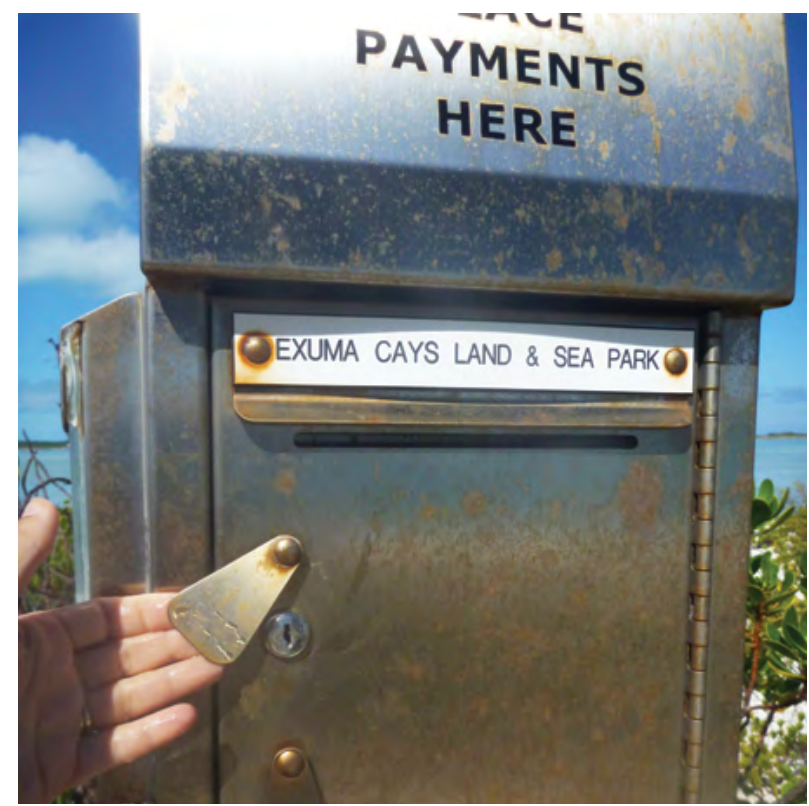

Exuma Cays, Bahamas, aire marine protégée pour la reconstitution des ressources : boîte de collecte des frais d'entrée

Source : Simon McArthur être tirés des frais d'exploitation sont décrites dans le tableau 23.5.

De nombreux exploitants se feront un plaisir d'envisager des accords partagés afin de réduire les coûts qu'ils auraient autrement à payer au gestionnaire de l'aire protégée. Une plus grande utilisation de cette approche profiterait conjointement au tourisme et à la gestion des aires protégées. La plupart des entreprises touristiques acceptent d'être facturées, mais comme les visiteurs, elles s'attendent à voir les fonds réinvestis dans la gestion des aires protégées et les services où les revenus sont collectés. Lorsque l'organisation chargée de l'aire protégée augmente les frais d'exploitation avec un préavis de moins d'un an, des impacts importants sur les entreprises peuvent se produire, les opérateurs travaillant avec des réservations à long terme, et ayant donc souvent déjà fixé les prix et reçu le paiement des produits vendus, et toute augmentation des frais pouvant être impossible à répercuter. 


\section{Prestations commerciales des organismes chargés des aires protégées}

Certains organismes de gestion des aires protégées choisissent de gérer leur propre activité touristique commerciale, et de percevoir des revenus grâce à des bénéfices commerciaux, comme SANParks en Afrique du Sud (SANParks, 2011). Les organismes chargés des aires protégées peuvent exploiter tout ce que fait l'industrie du tourisme, y compris la location d'équipement, la vente de nourriture, de boissons et de marchandises, et les services de guide. Habituellement, les organismes choisissent d'exploiter eux même leur activité touristique parce que :

- ils croient qu'ils peuvent générer plus de revenus que l'opérateur (en raison de l'avantage concurrentiel dont ils disposent) ;

- l'industrie touristique est peu intéressée ou ne dispose pas des capacités requises ;

- l'organisme veut maximiser le contrôle sur le produit ou le service.

Des politiques et procédures claires et une gestion solide sont nécessaires pour assurer un environnement opérationnel transparent, équitable et exempt de corruption (Font et al., 2004).

\section{Marketing}

La commercialisation des aires protégées doit être activement gérée par une organisation chargée des aires protégées. Grâce à cette gestion, la relation importante entre l'offre de destinations au sein d'un réseau d'aires protégées et la demande concernant leur utilisation peut être gérée de manière professionnelle. Il s'agit d'un moyen important par lequel les organisations chargées des aires protégées veillent à ce que les destinations ne soient pas envahies par un trop grand nombre de touristes, générant des impacts conséquents sur les valeurs de la biodiversité et la dégradation des sites. Cela peut également contribuer aux aspects sociaux et financiers à long terme d'une industrie touristique durable, en garantissant l'offre d'expériences de haute qualité aux visiteurs. Comment, quand et où les destinations des aires protégées sont commercialisées ne devrait pas être simplement délégué à l'industrie du tourisme. Un partenariat de travail positif et actif doit être établit entre les organisations de tourisme et les organisations chargées des aires protégées.

Le marketing est l'un des outils les plus puissants pour une gestion efficace des visiteurs et du tourisme. Le marketing consiste en beaucoup plus que la promotion et la vente. Il s'agit de créer, de promouvoir et de fournir des biens et des services aux consommateurs et aux entreprises (Kotler,
2003). Le marketing conventionnel est basé sur le principe des cinq « $\mathrm{P} »($ Aaker, 1995).

1. Quels services et expériences offrir et à qui (produit) ?

2. Combien facturer, à qui et dans quelles conditions (prix) ?

3. Où proposer le produit (placement) ?

4. Qui livrera le produit et comment seront traités les clients (personnes) ?

5. Comment sensibiliser et créer un intérêt envers le produit (promotion)?

Nous nous concentrerons ici sur les éléments stratégiques suivants pour un marketing efficace :

- Étude des visiteurs et du marché

- Segments de marché

- Positionnement et image de marque de la destination

- Promotion efficace.

\section{Étude des visiteurs et du marché}

Il n'existe pas deux visiteurs identiques en ce qui concerne qui ils sont, ce qu'ils veulent, ce qu'ils ont fait, ce qu'ils ont pensé de l'aire protégée et à qui ils en ont parlé. L'étude des visiteurs est conçue pour répondre à ces questions et, par la suite, permettre aux gestionnaires de savoir quoi offrir, à qui, et pourquoi. Sans cette connaissance, les gestionnaires d'aires protégées finissent par essayer d'être " tout pour tous ", impressionner peu de gens et finir totalement frustrés, eux-mêmes. Certains des outils de recherche à disposition des gestionnaires d'aires protégées sont présentés dans le tableau 23.6. Le comptage des visites et les questionnaires simples sont généralement entrepris par le gestionnaire de l'aire protégée, mais les autres outils, plus sophistiqués, nécessiteront généralement l'intervention de consultants en tourisme et en études de marché. Dans leur choix d'un outil, les gestionnaires devront prendre en compte le compromis typique entre rentabilité et degré de perspicacité et de révélation susceptible d'être généré de manière fiable. Obtenir une expertise pour aider à déterminer cela est un investissement raisonnable, et souvent utile.

Les études de marché permettent d'échantillonner des non-visiteurs ou des visiteurs passés d'une aire protégée. Certaines de ces personnes pourraient être incitées à devenir des visiteurs, et certaines peuvent même mieux correspondre à l'aire protégée que certains visiteurs actuels. Les gestionnaires d'aires protégées utilisent des études de marché pour identifier les profils de ces non-visiteurs (en particulier leurs besoins et leurs désirs), puis déterminer quels profils pourraient être considérés comme des visiteurs potentiels pour qui concevoir des expériences, et à attirer vers l'aire protégée. Étant donné que les non-visiteurs sont plus 
Tableau 23.6 Outils pour l'étude des visiteurs

\begin{tabular}{|c|c|c|}
\hline $\begin{array}{l}\text { Outil d'étude } \\
\text { des visiteurs }\end{array}$ & Points forts & Limites \\
\hline $\begin{array}{l}\text { Comptage des } \\
\text { visites }\end{array}$ & $\begin{array}{l}\text { Le comptage du nombre de visiteurs donne des } \\
\text { indications sur le niveau d'utilisation et, dans } \\
\text { une certaine mesure, sur la nature de l'utilisation } \\
\text { (calendrier, durée du séjour, taille des groupes). } \\
\text { Le comptage des visites fournit des données } \\
\text { de référence pour identifier les tendances } \\
\text { historiques, les prévisions et la modélisation } \\
\text { économique et financière. }\end{array}$ & $\begin{array}{l}\text { Si il est utilisé seul, une trop grande importance } \\
\text { accordée au nombre de visiteurs peut être } \\
\text { dangereuse, car elle encourage à penser que } \\
\text { tous les visiteurs sont identiques. } \\
\text { Le comptage est rarement précis et a généré } \\
\text { d'énormes perceptions erronées (par exemple, } \\
\text { la fréquentation peut donner l'impression } \\
\text { d'augmenter, alors qu'en fait, l'augmentation est } \\
\text { due à un plus grand nombre de compteurs). }\end{array}$ \\
\hline $\begin{array}{l}\text { Observations } \\
\text { comportementales }\end{array}$ & $\begin{array}{l}\text { Très utile pour explorer ce qui est inconnu, en } \\
\text { complément à un autre outil d'étude utilisé comme } \\
\text { cadre de référence pour formuler sa structure. } \\
\text { Généralement utilisées pour cartographier les } \\
\text { déplacements des visiteurs, ce qu'ils font et } \\
\text { pendant combien de temps. Les observations } \\
\text { structurées anticipent le comportement et } \\
\text { consignent les données dans des tableaux } \\
\text { pouvant être analysés quantitativement. Les } \\
\text { observations non structurées tiennent compte de } \\
\text { tout ce qui se passe et peuvent permettre une } \\
\text { analyse qualitative. }\end{array}$ & $\begin{array}{l}\text { Généralement dépendantes de ressources } \\
\text { humaines, ce qui les rend coûteuses, en } \\
\text { particulier lorsqu'il y a peu de visiteurs et que } \\
\text { l'observateur doit être rémunéré. Nécessitent } \\
\text { une analyse minutieuse par la suite, et les } \\
\text { compétences d'analyse qualitative sont plus } \\
\text { difficiles d'accès. }\end{array}$ \\
\hline Questionnaires & $\begin{array}{l}\text { Des questions prédéfinies sont généralement } \\
\text { gérées sur papier, en ligne ou en face-à- } \\
\text { face, offrant un haut degré de contrôle sur } \\
\text { les données et la capacité d'analyser et de } \\
\text { comparer facilement les résultats, y compris par } \\
\text { des tests statistiques. }\end{array}$ & $\begin{array}{l}\text { Des questionnaires mal rédigés donnent des } \\
\text { résultats médiocres et peu fiables. Les résultats } \\
\text { peuvent être affectés par un ordre de questions } \\
\text { incorrect, des réponses optionnelles non } \\
\text { pertinentes et des questions mal formulées. } \\
\text { Les résultats peuvent être manipulés ou } \\
\text { mal interprétés en fonction des objectifs du } \\
\text { chercheur. }\end{array}$ \\
\hline $\begin{array}{l}\text { Interviews face-à- } \\
\text { face }\end{array}$ & $\begin{array}{l}\text { Semblable à un questionnaire en personne, } \\
\text { mais utilise généralement moins de questions. } \\
\text { L'objectif est d'amener le répondant à } \\
\text { parler plus librement, et donc, d'obtenir des } \\
\text { informations plus approfondies, telles que la } \\
\text { cause sous-jacente des problèmes ou la façon } \\
\text { dont une solution pourrait être développée et } \\
\text { mise en œuvre. }\end{array}$ & $\begin{array}{l}\text { Généralement dépendantes de ressources } \\
\text { humaines, ce qui les rend coûteuses, en } \\
\text { particulier pour le temps passé à se déplacer } \\
\text { vers chaque répondant pour une interview. Selon } \\
\text { le processus de sélection, choisir les personnes } \\
\text { interrogées les plus appropriées, qui ne sont pas } \\
\text { toujours celles qui sont au pouvoir ou qui ont un } \\
\text { profil élevé. }\end{array}$ \\
\hline $\begin{array}{l}\text { Groupes de } \\
\text { discussion }\end{array}$ & $\begin{array}{l}\text { S'appuyant sur l'interview face-à-face, un } \\
\text { groupe de personnes peut générer une plus } \\
\text { grande discussion et plus de révélations, } \\
\text { chacun ajoutant de la valeur aux contributions } \\
\text { des autres. }\end{array}$ & $\begin{array}{l}\text { Beaucoup plus coûteux que les questionnaires, } \\
\text { et nécessitent une préparation considérable } \\
\text { pour structurer la discussion, une expertise } \\
\text { considérable en matière de facilitation et un } \\
\text { temps considérable, par la suite, pour analyser } \\
\text { les résultats. }\end{array}$ \\
\hline Réseaux sociaux & $\begin{array}{l}\text { L'analyse des données des réseaux sociaux } \\
\text { sur les destinations des aires protégées est une } \\
\text { source d'information importante. }\end{array}$ & $\begin{array}{l}\text { Les données et recommandations d'utilisateurs } \\
\text { sont disponibles, par exemple, à partir } \\
\text { d'applications logicielles telles que Yelp. }\end{array}$ \\
\hline
\end{tabular}

Sources : Adapté de Hall et McArthur (1998) ; Yeo (2005)

difficiles à trouver, et qu'il sera plus compliqué d'interagir avec eux, les études de marché utilisent généralement des questionnaires en ligne pour identifier les marchés potentiels, puis des groupes de discussion pour affiner les besoins de recherche et pour tester de nouvelles idées. Ce travail est parfois effectué par des consultants en tourisme et en études de marché, sous contrat avec le gestionnaire de l'aire protégée.

\section{Segments de marché et marchés cibles}

Le marketing de masse consiste en une production de masse, une distribution de masse et une promotion de masse d'un 
produit vers tout le monde (Tynan et Drayton, 1987). Le marketing de masse crée le plus grand marché potentiel, entraînant les coûts potentiels les plus bas, entraînant, à leur tour, des prix plus bas ou des marges plus élevées (Aaker, 1995 ; Dibb et Simkin, 2009). Le marketing de masse ne fonctionne pas pour les aires protégées parce que leur législation les empêche de pouvoir satisfaire tout le monde. Le marketing de masse peut amener certaines personnes à venir dans une aire protégée pour se livrer à des activités susceptibles de compromettre le site et les autres visiteurs.

L'alternative consiste à diviser le marché de masse en segments de marché, et à choisir les segments dont les besoins correspondent le mieux au produit, c'est à dire, les marchés cibles (Hunt et Arnett, 2004 ; Yeo, 2005). À partir de là, le gestionnaire peut concentrer le développement expérientiel, la promotion et la tarification sur les besoins du marché cible. Le suivi des visiteurs peut alors inclure des questions permettant d'identifier les répondants, afin de refléter les caractéristiques des marchés cibles, puis de traiter leurs réponses à d'autres questions avec une plus grande importance (comme la satisfaction et la probabilité de retour ou de recommandation).

Un segment de marché est un groupe de personnes présentant des caractéristiques similaires, et en particulier un ensemble analogue de besoins (Yankelovich et Meer, 2006). Les segments de marché sont généralement divisés en :

- géographique (résidence et lieu de travail par zone locale, région, État, pays ou continent) ;

- démographique (âge, sexe, taille de la famille, cycle de vie, revenus, profession, éducation, etc.) ;

- psychologique (attitudes, risque, motivation, etc.) ;

- caractéristiques psychographiques (mode de vie, activités, intérêts, opinions, besoins et valeurs) ;

- comportemental (fidélité à une marque, taux d'utilisation, avantages recherchés et utilisés).

Lindustrie du tourisme utilise généralement une segmentation basée sur des caractéristiques géographiques et démographiques, car elles sont simples et peu coûteuses à utiliser. Cependant, ces caractéristiques ont une valeur limitée lors del'élaboration de la marque, du positionnement, du produit ou de l'expérience d'une aire protégée, car elles sont trop génériques. La segmentation du marché offre un certain nombre d'utilisations pratiques pour le gestionnaire d'aires protégées, y compris la possibilité de :

- définir le marché du point de vue du consommateur ;

- rationaliser les politiques pour les marques et produits existants (afin d'améliorer la compétitivité et la part de marché) ;

- positionner une gamme de marques et de produits ;

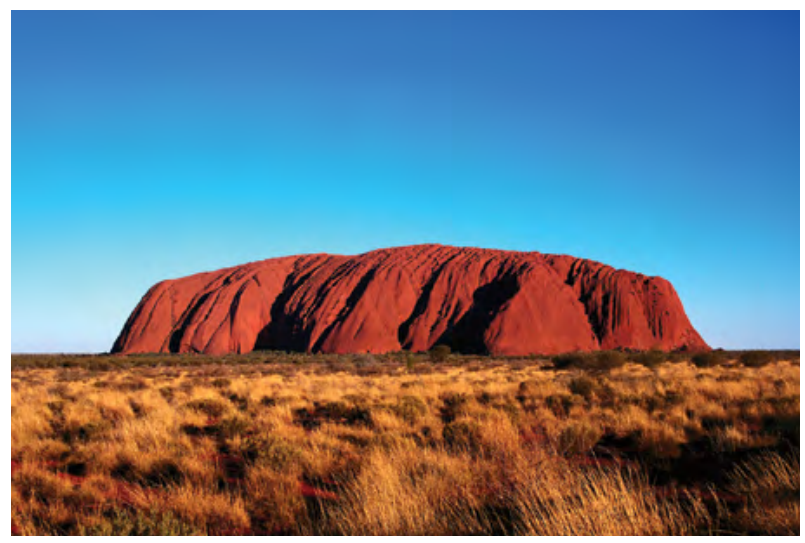

Figure 23.5a Parc national et site du Patrimoine mondial d'Uluru-Kata Tjuta, Australie : image standard

Source : Melbourne Business Community (2013)

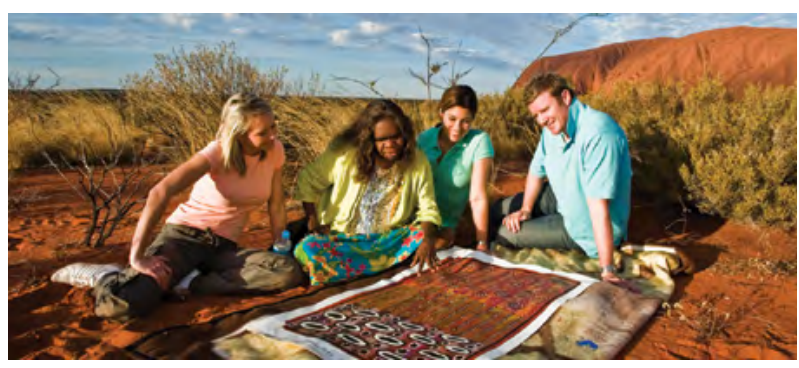

Figure 23.5b Parc national et site du Patrimoine mondial d'Uluru-Kata Tjuta, Australie :

l'« Expérience Uluru »

Source : Simon McArthur (1999)

- identifier les lacunes du marché offrant de nouvelles possibilités (Lunn, 1978, cité dans Tynan et Drayton, 1987).

Il est possible d'élaborer un questionnaire afin de déterminer de quels segments de marché proviennent les visiteurs d'une aire protégée. Une autre façon pratique d'utiliser les segments de marché consiste à suivre la représentation des marchés cibles par rapport aux autres marchés parmi les visiteurs d'une aire protégée.

\section{Positionnement et image de marque de la destination}

Une marque est la source d'une promesse distinctive pour les clients d'un produit, d'un service ou d'un lieu (Baker, 2012). Déterminer une marque pour une aire protégée est plus complexe que la plupart des gestionnaires ne le prévoient, et il s'agit également d'une initiative dont la pertinence doit être soigneusement examinée. Fondamentalement, toute marque développée pour une aire protégée doit être compatible avec son statut d'aire protégée. Pour une destination spécifique dans une aire protégée, la marque comprend également la façon dont les gens interprètent la 


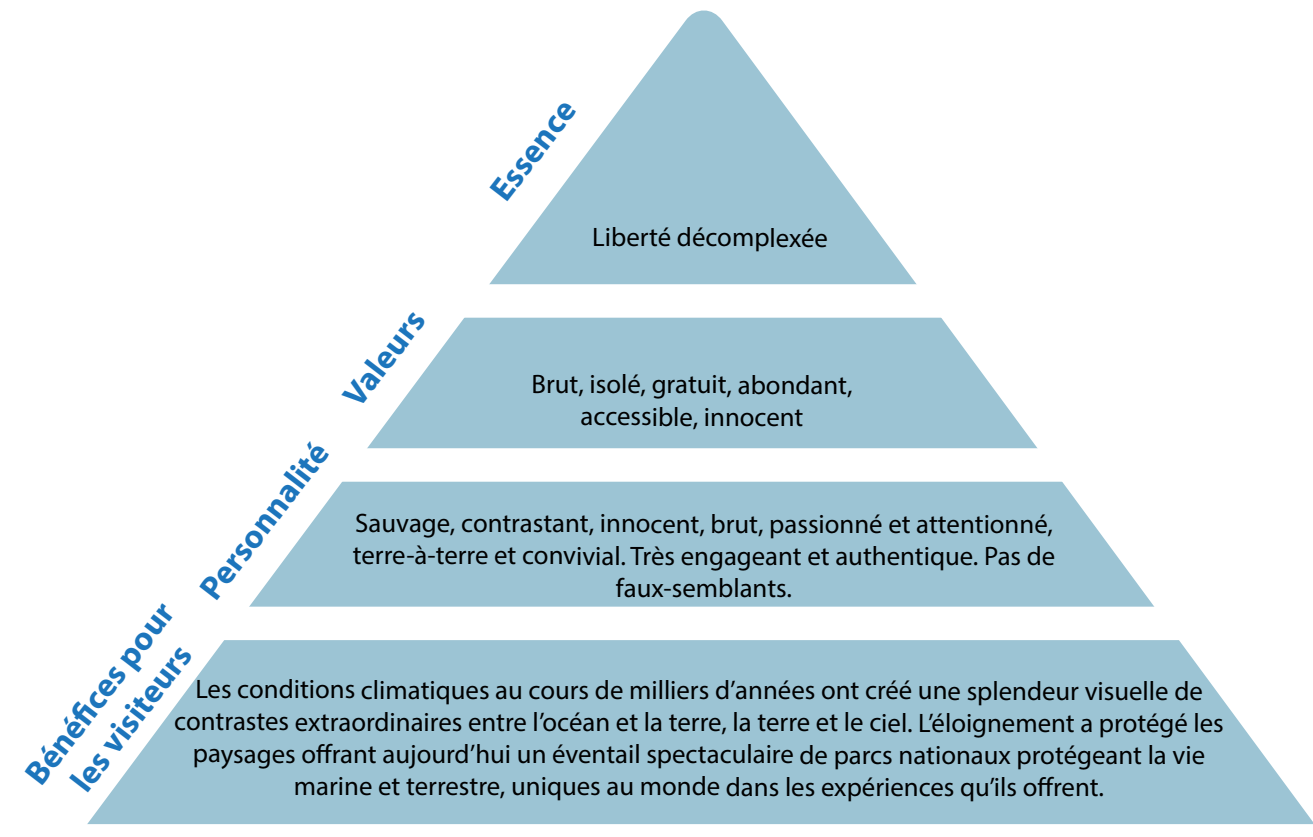

$1500 \mathrm{~km}$ de littoral, le long du point le plus à l'ouest de l'Australie, offrant une saisonnalité migratoire extraordinaire, liée aux variations climatiques uniques de la région. Quelques-uns des ciels les plus clairs du monde pour observer les stromatolites, le mont Augustus, des parcs nationaux offrant une biodiversité d'espèces de mégafaune et une vie marine phénoménale. Des requins baleines, des raies Manta et des tortues nichent le long de la côte de Ningaloo. Des herbiers marins dans un récif de corail frangeant abritent des Dugongs. Les contrastes, l'isolement et l'interaction font de ce paysage unique un vrai site du Patrimoine mondial.

Figure 23.4 Pyramide de positionnement de la marque, Ningaloo-Shark Bay, Australie

Source : Adapté de Tourism Australia (2010)

destination pour eux-mêmes (Aaker, 1997), de sorte que des consultations et des études de marché considérables sont nécessaires pour comprendre comment les gens perçoivent un site et sa marque.

À partir de consultations et de la recherche, une pyramide de marque est alors créée (figure 23.4). Les deux derniers niveaux de la pyramide sont les principaux attributs de la destination et représentent les avantages pour le visiteur. La distillation commence alors, et une personnalité est créée pour la marque. De cette personnalité de marque émergent la valeur de la marque et, par la suite, l'essence de la marque. Lessence de la marque, est le cœur et l'âme de la marque, et se traduit souvent par une phrase concise ou slogan. Par exemple, l'essence de la marque de Parks Victoria (Australie) est " Healthy Parks, Healthy People " ("Des parcs sains, des hommes sains »). Les autres éléments incluent un logo, une image photographique, un style d'écriture, des polices de caractères et des couleurs.

Un ensemble unique de stimuli visuels, auditifs, et autres, aident à communiquer la marque et façonnent les perceptions du marché. Deux des éléments de communication les plus utiles pour une aire protégée sont le slogan et une photographie, qui doivent tous deux être utilisés sans relâche et de manière cohérente. Un logo n'est pas essentiel à la commercialisation d'une aire protégée (mais il est important pour l'image de marque de l'organisme). Tout ce qu'un gestionnaire d'aires protégées fait en collaboration avec ses partenaires et ses parties prenantes devrait être conçu pour offrir en permanence cette perception de marketing. Plus les gens seront conscients d'une marque, plus elle aura de valeur ou d'équité, et donc plus une organisation pourra l'utiliser pour guider ses propres objectifs. La marque peut également être très utile comme cadre de référence pour envisager le développement de nouvelles expériences pour les visiteurs à partir de la question : cette option reflète-t-elle ou dilue-telle notre marque?

Une fois que le gestionnaire a développé la marque, il doit la positionner. Pour le gestionnaire d'aires protégées, le positionnement est l'art de développer et de communiquer les différences significatives entre les offres de son aire et celles de ses concurrents desservant des marchés similaires (Baker, 2012). D'autres façons de positionner une aire protégée sont décrites dans le tableau 23.7. La clé pour décider de la position est l'alignement entre opportunités touristiques durables des aires protégées et besoins du marché.

\section{Promouvoir l'expérience des visiteurs}

L'industrie du tourisme s'est toujours considérée comme un fournisseur de produits touristiques vendables, tels que des visites, des attractions, des hébergements ou des restaurants. 
Tableau 23.7 Positionnement d'une aire protégée

\begin{tabular}{|l|l|}
$\begin{array}{l}\text { Alternative de } \\
\text { positionnement }\end{array}$ & $\begin{array}{l}\text { Un élément qui est le plus grand, le plus petit, le plus haut, le plus court, le plus } \\
\text { ancien, le plus rapide, le plus prolifique, le plus dangereux, le plus venimeux ou un } \\
\text { excellent représentant de sa catégorie, et ainsi de suite. }\end{array}$ \\
\hline Attribut d'unicité & Rare, vulnérable, en danger, sous pression, en voie de disparition. \\
\hline Rareté & $\begin{array}{l}\text { Importance locale, régionale ou nationale de la désignation. } \\
\text { Utilise l'inscription au Patrimoine mondial. }\end{array}$ \\
\hline Classe de produit & $\begin{array}{l}\text { Air pur ou eau pure, absence de foule, sentiment de liberté, lien avec le patrimoine } \\
\text { familial. }\end{array}$ \\
\hline $\begin{array}{l}\text { Besoin ou avantage de } \\
\text { l'utilisateur }\end{array}$ & \begin{tabular}{l} 
Aventurier, confiant, preneur de risques. \\
\hline vissociation avec le mode de \\
vie
\end{tabular} \\
\hline $\begin{array}{l}\text { Association contemporaine } \\
\text { célère avec le produit }\end{array}$ & $\begin{array}{l}\text { Lieu d'un tournage ou d'un événement célèbre. } \\
\text { Lieu où une personnalité célèbre a vécu ou a fait quelque chose d'important. }\end{array}$ \\
\hline Rapport qualité prix & $\begin{array}{l}\text { Comparer l'expérience interprétative au prix d'une entrée de cinéma ou de parc } \\
\text { d'attractions. }\end{array}$ \\
\hline Rétroaction positive & $\begin{array}{l}\text { Utilisez un haut niveau de rétroaction positive pour suggérer que si l'expérience a si } \\
\text { bien fonctionné pour les visiteurs précédents, elle devrait également fonctionner pour } \\
\text { les futurs visiteurs. }\end{array}$ \\
\hline
\end{tabular}

La plupart des gestionnaires d'aires protégées considèrent traditionnellement leur rôle comme celui d'accepter certaines activités et de mettre à disposition des visiteurs des infrastructures et des installations. Au cours de la dernière décennie, les deux secteurs ont entrepris d'investir davantage dans la création, la commercialisation et la revitalisation occasionnelle d'expériences touristiques (Wearing et al., 2007).

Une expérience touristique est bien plus qu'une activité ou un produit. C'est la combinaison de l'activité, du cadre, de l'interaction sociale et du lien personnel qui en résulte (Tourism Australia, 2012). Une expérience engage les sens. Elle est physique, émotionnelle ou spirituelle (ou les trois). Une expérience offre découverte et apprentissage, et crée des souvenirs forts. Les expériences vont au-delà de beaux endroits et de bons points de vues. Au lieu de cela, elles connectent les visiteurs à un site, son environnement et sa culture (Tourism Australia, 2012). Une façon d'améliorer ces expériences est de créer un sentiment d'appartenance au lieu basé sur le "genius loci ». Les touristes et visiteurs apprendront et apprécieront davantage une aire protégée s'ils ressentent une connexion au site qu'ils visitent. Ceci correspond à " la création d'un sentiment d'appartenance ", et se base sur les ressources naturelles et culturelles, et l'" esprit " du site. Le sentiment d'appartenance se base sur les personnes, les communautés locales vivant dans la région, leur savoir-faire et leurs traditions.

Pour qu'une aire protégée soit une destination touristique efficace, elle devra posséder :
- une/des expérience(s) principale(s), souvent désignée(s) dans le secteur du tourisme comme expérience épique ou emblématique, car elle se distingue par le fait qu'elle reflète totalement la marque et permet d'attirer l'intérêt des visiteurs et de les satisfaire ;

- des expériences complémentaires pour les visiteurs, reflétant idéalement une partie ou l'ensemble de la marque, et offrant des opportunités complémentaires à l'expérience principale ;

- des biens, services, produits et infrastructures annexes d'accès à l'aire protégée, tels que des aéroports et des routes d'accès, des stations-service, des parkings et des points d'information pour les visiteurs.

Si la commercialisation d'une aire protégée est efficace, elle peut surtout attirer des marchés cibles plutôt que des marchés de masse, et elle peut définir les attentes de ces personnes, avant leur arrivée (Hall et McArthur, 1998 ; Reid et al., 2008). Il est beaucoup plus facile et proactif de définir des attentes réalistes en matière de marketing que de réglementer inutilement, de durcir un site, ou d'essayer de changer le comportement des visiteurs, une fois sur le site.

La commercialisation d'une aire protégée à des fins touristiques devrait conduire le marché cible à participer à l'expérience principale, positionnée de façon compétitive et reflétant le slogan et la personnalité de la marque. De puissantes photographies doivent pouvoir démontrer ces éléments. Elles doivent refléter l'essence de l'expérience et de l'impact émotionnel qu'elle aura sur le marché cible. 
Malheureusement, la plupart des images utilisées manquent de puissance, de sorte que la garantie promotionnelle est perdue parmi les concurrents ou les autres promotions. Les figures $23.5 \mathrm{a}$ et $23.5 \mathrm{~b}$ comparent l'approche traditionnelle axée sur le paysage pour la commercialisation d'une aire protégée avec une approche contemporaine de marketing d'expériences fondé sur l'image. Idéalement, les gestionnaires d'aires protégées devraient engager un consultant en marketing touristique pour effectuer une séance photo qui capture tous les éléments. Après cela, l'image essentielle de l'expérience principale doit être servilement décrite et utilisée dans autant de campagnes de promotion que possible.

\section{Gestion des options de loisirs}

Un outil clé pour la planification et la gestion des options de loisirs est le "spectre des options de loisirs" (SOL). Le SOL se concentre sur le cadre des aires protégées dans lesquelles se déroulent des activités récréatives (Clark et Stankey, 1979). Un cadre est la combinaison de conditions physiques, biologiques, sociales et de gestion donnant de la valeur à un site. Ainsi, une option comprend les qualités fournies par la nature (végétation, paysage, topographie), les qualités fournies par le cadre socioculturel, les qualités associées à l'utilisation récréative (niveaux et types d'utilisation) et les conditions fournies par la gestion (aménagements, routes, règlements). De multiples possibilités impliquent un choix

\section{Encadré 23.1 Réduire les impacts sur les destinations touristiques}

I| existe en général quatre approches stratégiques pouvant être utilisées pour réduire les impacts négatifs des visiteurs sur les aires protégées :

1. Gérer l'offre d'options touristiques ou de visiteurs, par exemple, en établissant des quotas, ou en utilisant efficacement l'espace ou le temps disponible pour accueillir une plus grande utilisation.

2. Gérer la demande de visites, par exemple, par des restrictions sur la durée du séjour, le nombre total ou le type d'utilisations.

3. Gérer les capacités en ressources pour gérer l'utilisation, par exemple, en durcissant le site ou des emplacements spécifiques, ou en développant des installations.

4. Gérer l'impact de l'utilisation, par exemple, en réduisant l'impact négatif de l'utilisation en modifiant le type de cette utilisation, en la dispersant ou en la concentrant.

La principale question est de déterminer quel degré d'impact est acceptable. pour les amateurs de loisirs en plein air. Les gens doivent être conscients des options, et les options doivent inclurent les conditions souhaitées par les gens. Ainsi, les options sont une fonction de la préférence de l'utilisateur et un produit d'actions de gestion conçues pour fournir les paramètres souhaités et rendre les gens conscients de leur existence.

L'hypothèse sous-jacente au SOL est que la meilleure façon d'assurer la qualité des loisirs de plein air consiste à offrir un ensemble diversifié d'options (Clark et Stankey, 1979). Les visiteurs potentiels présenteront un large éventail de goûts et de préférences concernant les options de loisirs. Le fait de fournir des environnements divers, dont les niveaux de développement, d'accès, etc., varient, garantit qu'un plus large segment de visiteurs potentiels trouvera des expériences récréatives et touristiques de qualité. Il existe une énorme diversité en ce qui concerne les attentes des gens en matière d'activités récréatives, même pour des catégories spécifiques d'amateurs de loisirs en plein air. Tous les campeurs, randonneurs ou utilisateurs de la nature ne sont pas identiques. Les programmes de gestion des actifs axés sur des moyennes de goûts peuvent passer à côté de la cible, car ils ne tiennent pas suffisamment compte de la variation des goûts (Shafer, 1969).

La diversité assure la souplesse nécessaire pour atténuer les changements ou les perturbations dans le système de loisirs découlant de facteurs tels que le changement social (comme l'évolution de la structure d'âge d'une population) ou le changement technologique (comme l'augmentation de la disponibilité de véhicules récréatifs de plein air). Mais la diversité n'est qu'un moyen vers une fin. Des activités récréatives de qualité, produisant la satisfaction et les avantages souhaités pour les participants, sont l'objectif et la préoccupation des gestionnaires et des amateurs de loisirs.

Dans la gestion d'une diversité d'options de loisirs dans une aire protégée, la tâche de gestion à long terme la plus difficile pour les gestionnaires d'aires protégées est souvent de garder les milieux naturels dans leur état naturel. Le durcissement du site est souvent une réponse de gestion intuitive aux dommages causés à une destination touristique, mais c'est souvent justement la mauvaise réponse. Plus les milieux naturels seront endurcis, moins il y aura de sites naturels, et plus la diversité des sites de loisirs dans l'aire protégée diminuera. Au fur et à mesure que nous avançons dans le XXIe siècle, les sites de loisirs intacts deviendront de plus en plus rares et de plus en plus précieux. D'autres façons de gérer les impacts permettent de conserver les valeurs intactes des sites. Cela inclut le rejet professionnel des appels constants au développement. Les mesures pourront inclure l'établissement de limites au nombre de visiteurs et à la fréquence d'utilisation d'un site, une interdiction d'accès les jours de pluie, la rotation de l'utilisation des sites, etc. (encadré 23.1). Un danger de changement d'orientation 
existe lorsqu'un gestionnaire d'aire protégée termine son mandat et qu'un nouveau gestionnaire le remplace. Ce danger peut être minimisé par une planification claire et précise du SOL pour toutes les destinations touristiques au sein d'un réseau d'aires protégées, ainsi que par une initiation et une information approfondies pour les nouveaux membres du personnel.

\section{Services et installations destinés aux visiteurs}

Avant de fournir des services et des installations aux visiteurs pour une aire protégée, les gestionnaires doivent savoir pourquoi ils le font. La fourniture de services et d'installations dépendra, dans une large mesure, des possibilités souhaitées d'expérience pour les visiteurs, qui découlent à leur tour des objectifs de gestion sous-jacents. Ces objectifs incluent la protection, la conservation, l'éducation, les relations publiques, la recherche, la collecte de fonds et les loisirs, entre autres.

Bien que la plupart des gestionnaires reconnaissent que les touristes ont besoin d'une gamme de services et d'installations pour faire l'expérience d'un site, d'autres types de visiteurs doivent également participer à des services et des installations pour faire l'expérience du même site. Les écoliers auront besoin de nourriture, de toilettes et d'un endroit pour manger, les scientifiques auront besoin de guides, d'installations de laboratoire, de nourriture, de sentiers, de bibliothèques et de connexions internet, les journalistes devront être accompagnés par le personnel compétent du parc, les politiciens seront traités comme des VIP et requérons l'attention de gestionnaires d'information hautement qualifiés.

Souvent, les contributions que les visiteurs apportent à l'appui des objectifs du parc dépendent de s’ils ont apprécié leur séjour ou non. Si leur expérience a été positive, leur disposition à participer augmente exponentiellement (Ham, 2013). Si leur expérience a été négative, non seulement tout sentiment de coopération pourrait chuter, mais leur tendance provoquée à diffuser des recommandations négatives pourrait également nuire aux relations publiques du parc (Priskin et McCool, 2006 ; Cole et Williams, 2012).

Les gestionnaires de loisirs réclament une plus grande diversité d'options de loisirs, depuis le milieu du XXe siècle (Driver et al., 1987), afin d'améliorer la qualité, répondre aux demandes d'un plus grand nombre de visiteurs, les satisfaire davantage, et inciter les visiteurs à soutenir davantage les objectifs de gestion (Manning, 1985 ; Kohl, 2007). Les gestionnaires, cependant, ne peuvent pas garantir des expériences personnelles, mais seulement des options pour

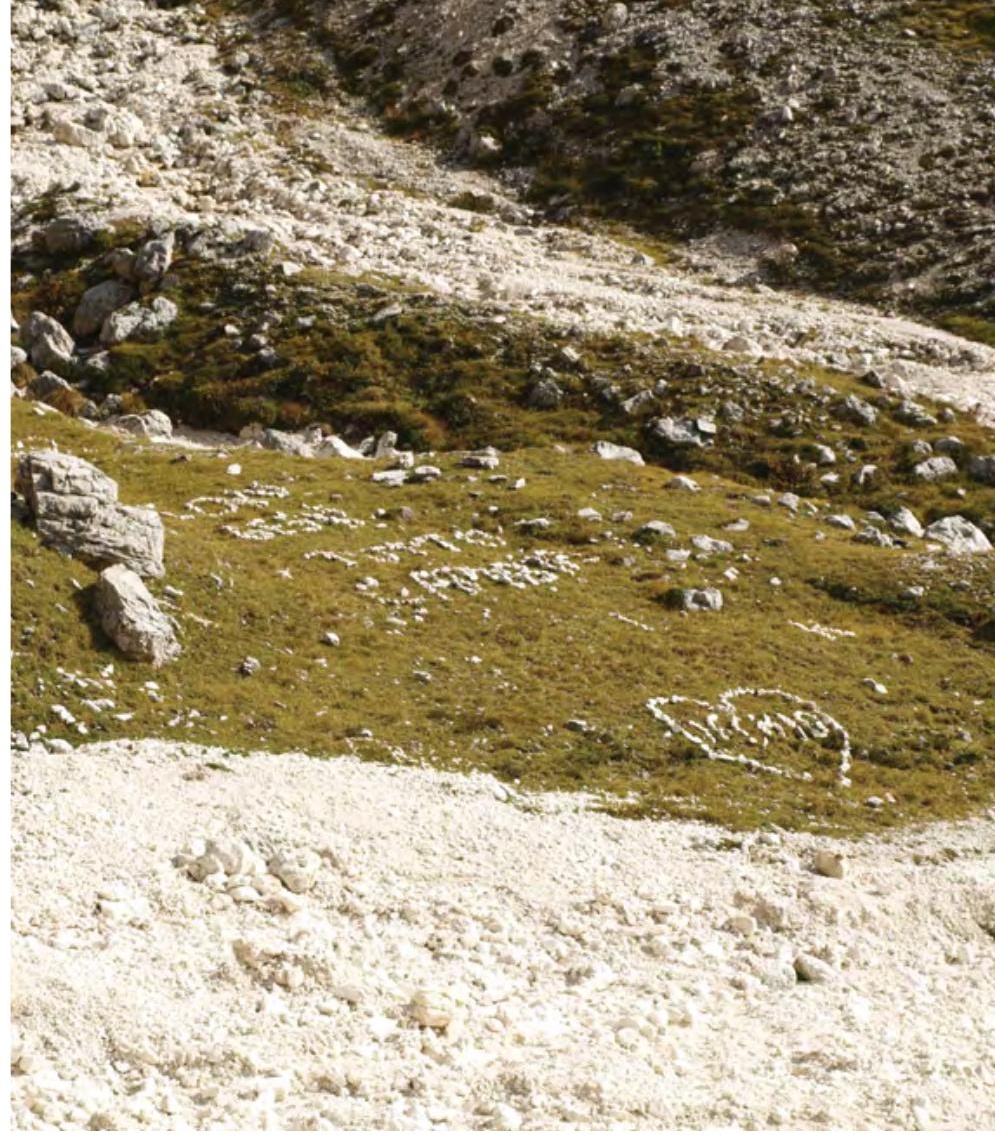

Graffiti réalisé avec des pierres dans un paysage

de montagne parsemé de rochers naturels, site du

Patrimoine mondial des Dolomites, Italie

Source : Graeme L. Worboys

les visiteurs de disposer d'expériences. Une expérience est une chose très personnelle, créé dans l'esprit du visiteur, et dépendante de nombreux facteurs. Pine et Gilmore (1999) définissent une expérience comme suit : (ÉVÉNEMENT [situation + activité + ressources] $\rightarrow$ RÉACTION $\rightarrow$ MÉMOIRE) $=$ EXPÉRIENCE

Les visiteurs ne recherchent pas seulement de plus en plus d'authenticité sur le marché (par exemple, une expérience plus primitive ou différente de leur mode de vie), mais le degré d'authenticité varie aussi considérablement, affectant la qualité de leur expérience. Pour cette raison, les gestionnaires doivent comprendre à la fois comment l'authenticité influence les expériences des visiteurs, et comment gérer pour améliorer ces opportunités.

L'expérience, et donc les services fournis (ou l'absence prévue de services fournis), est initiée bien avant l'arrivée du visiteur sur le site. Le visiteur façonne ses attentes à partir de l'information de sites web, de réseaux sociaux, de matériel promotionnel et du bouche-à-oreille. L'expérience se poursuit après le retour du visiteur à la maison, lorsqu'il se remémore ce qui lui est arrivé, et consulte tout matériel ou communication de suivi qu'il aura reçu de la part des prestataires de services ou des personnes qu'il aura rencontré en cours de route. Encore une fois, les gestionnaires d'aires protégées peuvent offrir des informations avant et après le voyage, afin de compléter l'expérience des visiteurs. D'autres prestataires de services courtisent également les voyageurs en offrant des services d'information, de transport, 
d'hébergement et autres services également susceptibles d'influer sur la qualité de l'expérience.

Bien que tous les visiteurs génèrent une expérience, ils ne les recherchent pas tous spécifiquement. Différents visiteurs peuvent être considérés comme des opportunités exigeantes à différents niveaux. Plus le niveau d'une " hiérarchie des demandes des visiteurs " est bas, plus la conscience de soi du visiteur sera grande (Driver et Brown, 1978). Ce modèle postule que les visiteurs exigent des activités (randonnée, canoë, observation d'oiseaux) dans certains contextes (aires naturelles non modifiées, sites partiellement ou totalement modifiés) pour réaliser certaines expériences (solitude, inspiration), pour finalement bénéficier de résultats sociopsychologiques spécifiques (améliorer les relations familiales, la forme physique, l'appréciation de la nature, la confiance en soi). À la lumière d'une telle diversité, il est impossible d'identifier un « visiteur moyen ». Au contraire, chaque visiteur recherche des configurations différentes de la demande (Cole et Williams, 2012).

Quel'on catégorise les opportunités d'expérience des visiteurs en utilisant le SOL, la segmentation du marché ou une autre classification, différents visiteurs rechercheront différents types d'expériences, et donc différentes combinaisons de services pour répondre à leurs besoins en matière de qualité, de confort, de sécurité, de paramètres environnementaux et de niveaux d'authenticité.

\section{Types de services et d'installations}

\section{Services et installations de soutien}

Ce sont les types de services et d'installations fournis pour aider à soutenir, maintenir et rétablir les besoins «fondamentaux » des visiteurs. Ce qui constitue un besoin «fondamental » dépend évidemment du contexte, les besoins " fondamentaux " de certains étant considérés comme un " luxe " par d'autres, ou dans d'autres contextes. Par conséquent, les services et installations de soutien basiques pourraient inclure des toilettes à fosse et le " luxe " pourrait être un accès à de l'eau potable. Les services de soutien et installations appropriées peuvent être complexes et englober une diversité de services et d'installations, comme on le voit dans certains centres d'accueil. Il est important que les gestionnaires déterminent avec quels types de besoins, de désirs et d'attentes les visiteurs peuvent arriver, et comment ils peuvent les adapter à la réalité des installations appropriées susceptibles d'être fournies. C'est pourquoi une planification et un zonage fondés sur le spectre des options récréatives sont si importants dans les aires protégées.

\section{Services et installations d'orientation}

Il est essentiel que les gestionnaires sachent de quels types de services et installations d'orientation les touristes peuvent avoir besoin. Ces types de services et d'installations pourraient inclure une signalisation directionnelle, des brochures d'information (tarifs, heures d'ouverture, procédures, billetterie, informations de contact, etc.), des rangers et des guides, des points de rencontre désignés, des sites web, des cartes, des lignes d'information téléphonique, des applications et autres techniques susceptibles d'aider à garder les visiteurs orientés dans le temps et dans l'espace.

\section{Services et installations de sûreté et de sécurité}

Cette catégorie d'équipements et de services permet aux personnes d'accéder à des endroits qu'ils auraient autrement évité en raison d'un danger physique ou d'obstacles sociaux. Souvent, ils passent inaperçus et sont sous-évalués par les visiteurs, comme la mise à disposition de gardes de parc et de contrôles de périmètre, mais ils doivent être intégrés dans les coûts globaux. Les exemples incluent les systèmes de sécurité électroniques tels que les caméras de surveillance, la signalisation expliquant les règles et recommandations en matière de sécurité et le matériel éducatif destiné aux visiteurs.

\section{Services et installations d'interprétation}

Linterprétation est une approche de communication qui relie les gens intellectuellement et émotionnellement avec les objets interprétés pour approfondir leur appréciation de ces objets. Dans le contexte des aires protégées, l'objet est le patrimoine d'un site. Une appréciation plus profonde contribue à une attention plus grande et une disposition à aider à la réalisation des objectifs de gestion. Les services et installations d'interprétation incluent tous les services et installations éducatifs et autres non déjà mentionnés, améliorant et soutenant l'expérience des visiteurs. Les exemples incluent les guides d'interprétation, la signalisation, les expositions, les vidéos, les documents éducatifs imprimés, les guides automatisés, les représentations théâtrales, les émissions de radio, les démonstrations d'histoire vivante ou l'interprétation itinérante. De nombreuses aires protégées sont fortement axées sur l'éducation, y compris par des programmes directement liés aux programmes scolaires.

\section{Services et installations multiples}

Souvent, les services et installations fournis se chevauchent et sont présents dans les mêmes médias et espaces. Par exemple, les centres d'accueil combinent souvent toutes les zones, en offrant des expositions d'interprétation (interprétation), des bureaux d'information (orientation), des toilettes et des services de vente de nourriture (restauration), des 
installations pour personnes handicapées (par exemple, des sentiers pour personnes aveugles ou en fauteuils roulants sortant souvent des centres d'accueil), des boutiques (interprétation et restauration) et un accès au personnel.

\section{Gestion de l'impact des visiteurs}

Le nombre croissant de problèmes d'impact des visiteurs auxquels sont confrontés, aujourd'hui, les gestionnaires d'aires protégées se caractérise par un éventail de complexités et d'incertitudes, et se produit dans un contexte de conditions environnementales changeantes et de capacités organisationnelles variables. Par conséquent, les gestionnaires d'aires protégées doivent comprendre la nature des problèmes et les possibles solutions. Dans cette section, nous examinerons une gamme d'impacts des visiteurs et explorerons la variété des cadres d'évaluation et de gestion de ces impacts. Les impacts sociaux et communautaires du tourisme sont une considération importante dans la planification et la réponse aux impacts des visiteurs sur les aires protégées.

\section{Impact des visiteurs sur l'environnement}

Les visiteurs, dans les aires protégées, peuvent avoir un large éventail d'impacts environnementaux, y compris sur les sols, les plantes, les animaux et les systèmes aquatiques (Liddle, 1997 ; Newsome et al., 2002). Pour les animaux, ces impacts peuvent inclure :

- modifications du comportement et de la physiologie des animaux, telles que le déclenchement des réactions d'envol chez les oiseaux ;

- changements dans les habitudes et le succès de reproduction, tels que les dommages causés aux oiseaux nichant au sol ;

- introduction d'animaux nouveaux (animaux sauvages ou domestiques, y compris les animaux de pâturage) ;

- dommages et élimination des habitats ;

- mortalité des animaux, délibérément (pêche, chasse) ou accidentellement (mortalité due aux véhicules).

Les impacts sur les plantes peuvent inclure :

- dommages directs causés par le piétinement;

- élimination de végétation pour la construction d'infrastructures ;

- changements de composition suite à l'introduction de nouvelles espèces (mauvaises herbes, plantes de jardin);
- changements dans l'environnement abiotique affectant les plantes (sol, lumière, vent, nutriments, etc.);

- fragmentation des habitats par les sentiers et autres infrastructures ;

- incendies à l'échelle des paysages déclenchés délibérément (pyromanes) ou accidentellement (feux de camp) par les visiteurs.

Les impacts sur les systèmes aquatiques incluent les changements dans la teneur en oxygène, la turbidité, le débit, le ruissellement, la pollution et les prélèvements d'eau, ainsi que les changements dans les nutriments liés aux activités aquatiques (baignade, navigation de plaisance, etc.) et dans les zones entourant les rivières, les ruisseaux et les lacs (camping, piétinement, etc.). Les impacts sur les sols incluent le compactage, les changements dans les nutriments, y compris la nitrification, le ruissellement, l'érosion et la perte des sols, et jusqu'à des changements à grande échelle tels que les glissements de terrain.

Les types et le degré des impacts varie avec la nature des activités, l'utilisation saisonnière, l'intensité d'utilisation, le comportement des utilisateurs et la résilience des écosystèmes. Par exemple, il a été démontré que certains types d'activités, comme l'équitation, ont une plus grande portée et une plus grande intensité d'impact que d'autres, comme la randonnée. Les activités des visiteurs, à certaines périodes de l'année, ont plus d'impact qu’à d'autres. Par exemple, le bruit et la pollution lumineuse peuvent avoir un impact plus important sur le comportement des animaux pendant la saison de reproduction qu'à d'autres moments. De même, les dommages causés à la végétation par le piétinement peuvent être plus importants pendant la saison de floraison que lorsque les plantes sont en dormance.

Une plus grande utilisation tend à causer plus de dommages, mais la forme de cette relation peut varier (Monz et al., 2013). Par exemple, la relation peut être curviligne, la plupart des dommages se produisant avec la première utilisation, et après une certaine durée d'utilisation les dommages supplémentaires étant limités. Elle peut être linéaire, lorsque les dommages sont constamment liés à la quantité d'utilisation. Elle peut être sigmoïdale, lorsque des dommages limités à de faibles niveaux d'utilisation augmentent rapidement, puis se stabilisent à nouveau. La forme que prend cette relation est très importante pour les gestionnaires, car elle affecte les options de gestion les plus efficaces, telles que le choix entre une utilisation dispersée ou une utilisation concentrée (Monz et al., 2013). En raison de différences de comportement, certains visiteurs peuvent causer plus de dégâts que d'autres. Les visiteurs peuvent varier dans leur connaissance, leur capacité et leur volonté de se conformer aux pratiques d'impact minimum. 


\section{Étude de cas 23.1 Initiative zéro déchet sur le sentier de trekking de Sikkim Himalaya, Inde}

Le gouvernement du Sikkim a créé le parc national de Khangchendzonga en 1977. Avec une superficie de 1784 kilomètres carrés, et bordant le Népal et le Tibet, le parc présente une altitude allant de 1829 à 8586 mètres au-dessus du niveau de la mer, et comprend le mont Khangchendzonga, la troisième plus haute montagne du monde. II s'agit d'un hotspot de biodiversité, qui abrite des espèces menacées, comme la panthère des neiges (Uncia uncia). C'est aussi un paysage sacré, les communautés locales le considérant comme une divinité protectrice. Tous les cours d'eau, les lacs, les collines et les grottes sont considérés comme sacrés, et selon la croyance, ils auraient été bénis par le guru bouddhiste Padma Sambhava. C'est pour cette raison que les communautés locales se sont constamment opposées aux propositions de construction de projets hydroélectriques dans la région.

Le parc a été ouvert aux touristes en 1982, afin de promouvoir le tourisme d'aventure et créer des emplois locaux. Au départ, seuls quelques groupes organisés visitaient le parc, car il était très difficile d'obtenir des permis. En 1992, le système de permis a été assoupli, entraînant une augmentation du nombre de visites. Au cours de cette période, cependant, certains touristes et exploitants se préoccupaient moins de la conservation. Cela a abouti à une série d'impacts, notamment l'accumulation de déchets, la déforestation pour le bois de cuisson, de chauffage et les feux de camp, le surpâturage par les animaux de bât, la bio-piraterie par les visiteurs collectant des plantes médicinales, des fleurs alpines, des graines et des insectes, le camping sauvage dans les prairies de haute altitude, le braconnage et la chasse d'animaux sauvages par le personnel de trekking, et la pollution des zones humides de haute altitude. La population locale s'est indignée de cette profanation du paysage sacré.

Pour s'attaquer à ces problèmes, une organisation non gouvernementale (ONG) communautaire, le Khangchendzonga Conservation Committee, a été créée en 1996, à Yuksam, la base de trekking du parc. Ce comité a mobilisé la communauté locale et les acteurs du tourisme pour entreprendre une série d'activités de conservation. Cela comprenait la promotion d'activités écotouristiques communautaires, telles que des campagnes de nettoyage des sentiers de trekking, l'éducation à la conservation, la formation des acteurs du tourisme, la gestion des déchets, le suivi

Les infrastructures mises à la disposition des visiteurs ont également un large éventail d'impacts, y compris pendant la construction, l'entretien et l'utilisation. Ces impacts peuvent être à court terme et localisés, mais peuvent également être graves, à long terme et à grande échelle. Une sélection, une conception et une maintenance soigneuses des infrastructures peuvent réduire considérablement leur impact sur l'environnement. Une question clé pour les gestionnaires d'aires protégées est de savoir comment minimiser et améliorer ces impacts environnementaux des visiteurs (voir, par exemple, l'étude de cas 23.1). de la bio-piraterie et l'interdiction de l'utilisation du bois de chauffage à l'intérieur du parc. Un code de conduite pour la conservation a été élaboré, des stratégies visant à minimiser les impacts du pâturage par les animaux de bât et des sites de camping appropriés ont été introduits. Des séjours chez l'habitant (parmi les premiers en Inde) ont également été développés comme un moyen pour les familles locales d'augmenter leurs revenus.

Pour résoudre le problème des déchets dans le parc, en 2007, une campagne de nettoyage a été organisée le long du populaire sentier de trekking et des campings. Le personnel touristique, y compris les porteurs, les opérateurs d'animaux de bât, les guides et les cuisiniers, ainsi que les membres de la communauté et les enseignants et étudiants, y ont participé. Par la suite, plusieurs campagnes de nettoyage des sentiers ont été organisées par le département du tourisme, les agents de voyages et certains particuliers.

Conscient, toutefois, que cette solution seule n'était pas une solution à long terme, le Comité a conceptualisé un nouveau système appelé "Zero Waste Trekking Trail » (Sentier de trekking zéro déchet). Dans le cadre de cette initiative, tous les visiteurs du parc doivent rapporter tous les déchets non biodégradables déclarés sur leur formulaire d'inscription. À Yuksam, où ils terminent le sentier de trekking, des fonctionnaires, après avoir vérifié que tous ces déchets ont effectivement été retirés du parc, les séparent en boîtes de conserve, batteries et déchets médicinaux, tissu, papier aluminium et paquets de nouilles, plastiques, papier et cartons.

Ces déchets sont ensuite transportés dans un " centre de récupération des ressources " voisin, où ils sont nettoyés et séparés. Tous les articles recyclables sont vendus, tandis que les articles tels que les paquets de biscuits et de chips, non recyclables, sont déchiquetés et utilisés pour fabriquer des coussins ou autres produits. Certains papiers recyclés sont fabriqués à partir de vieux papiers et cartons. Le centre est lui-même devenu une destination touristique populaire, fournissant un message fort que le trekking ne doit pas se faire au détriment de l'environnement et des communautés locales. Grâce à ces efforts, les sentiers du parc, utilisés par environ 6500 visiteurs chaque année, sont pratiquement exempts de déchets.

Pema Gyaltshan Bhutia, Khangchendzonga Conservation Committee

\section{Impacts sociaux et culturels des visiteurs}

Les communautés locales sont souvent considérées comme les bénéficiaires du tourisme, en particulier en termes d'avantages économiques découlant d'emplois et de la fourniture de services et de produits aux visiteurs des aires protégées. Le tourisme dans les aires protégées, cependant, présente souvent des impacts sociaux négatifs, tels que des changements dans le statut économique et social, les routines quotidiennes, la qualité de vie, la circulation, le bruit, la 
sécurité et l'accès aux sites traditionnels. Travailler avec ou par l'intermédiaire des communautés locales pour identifier et gérer la nature des impacts du tourisme sur l'aire protégée peut être une entreprise complexe (voir l'étude de cas 23.2). Les évaluations d'impact social et environnemental sont des outils utiles pour aider à comprendre, prévoir et gérer les impacts potentiels du tourisme sur les aires protégées et les développements connexes. L'évaluation de l'impact social se concentre sur les impacts potentiels de différents scénarios sur les individus et les communautés (Brown et al., 2006). Lévaluation des impacts environnementaux est souvent effectuée dans un contexte plus général, afin d'inclure les effets négatifs et positifs potentiels des aménagements dans les aires protégées sur les composantes naturelles, culturelles, sociales et économiques (Parcs Ontario, 2005). Cette approche plus holistique reconnait que toutes ces composantes sont interdépendantes, et doivent donc être considérées simultanément.

Les impacts sociaux ne se limitent pas aux communautés locales, mais se produisent également parmi les visiteurs. Les activités, le comportement et les infrastructures offerts à certains visiteurs peuvent avoir une incidence positive ou négative sur l'expérience d'autres visiteurs. Un défi majeur pour les gestionnaires est de gérer les conflits potentiels entre les différents types de visiteurs. Les conflits entre visiteurs portent souvent sur des questions telles que la pertinence d'une activité, ses impacts environnementaux, ses impacts sociaux et le danger qu'elle peut représenter pour les autres utilisateurs. Dans certains cas, le fait d'autoriser un type d'activité peut faire que certains visiteurs évitent l'aire protégée. L'observation des oiseaux et la chasse dans une aire protégée privée, par exemple, ne sont pas des activités hautement compatibles, et le fait de permettre la chasse peut entraîner le renoncement d'autres visiteurs.

\section{Répondre à l'impact des visiteurs}

Léventail d'impacts environnementaux et sociaux potentiels découlant de l'utilisation faite par les visiteurs présente des défis nécessitant une attention de gestion. Ces impacts peuvent (Farrell et Marion, 2002) :

- compromettre la réalisation du mandat et des objectifs de l'aire protégée ;

- affecter négativement les valeurs naturelles et culturelles, plusieurs impacts pouvant combiner leurs effets ou être cumulatifs au fil du temps ;

- entraîner des conséquences inattendues, telles que la diminution des visites et des bénéfices économiques, cela pouvant, à son tour, affecter le bien-être des communautés locales.
Un certain nombre de mesures proactives peuvent être mises en place pour éviter les effets non intentionnels. Celles-ci s'articulent autour d'éléments de l'approche de gestion adaptative, c'est-à-dire : entreprendre une bonne planification, dès le départ, mettre en œuvre les mesures prescrites, réaliser un suivi des effets positifs et négatifs sur les valeurs, évaluer les résultats et en tirer des enseignements, et ajuster les mesures de gestion pour améliorer et affiner les interventions nécessaires (voir les chapitres 8 et 13).

La gestion active des impacts des visiteurs peut aider à minimiser leur effet (Farrell et Marion, 2002). Un certain nombre de cadres de gestion ont été mis en place pour aider les gestionnaires d'aires protégées à minimiser les impacts des visiteurs. Un cadre de gestion efficace est un processus par étapes permettant aux gestionnaires et aux planificateurs d'aires protégées d'interpréter et d'expliquer les enjeux (McCool et al., 2007). Un cadre aide les gestionnaires à :

- identifier les compromis entre l'offre d'options de loisirs et les impacts économiques locaux qui en résultent et la protection des valeurs de la biodiversité ;

- apprécier et prendre en compte la complexité ;

- accueillir l'éventail de parties prenantes possédant des intérêts dans le domaine ou la question.

Les décideurs doivent évaluer la pertinence des cadres pour chaque utilisation spécifique. Les chercheurs ont fourni cinq critères pour évaluer la pertinence d'un cadre pour résoudre les problèmes de gestion des visiteurs et décrire les conditions propices à la réussite de leur demande ( $\mathrm{McCool}$ et al., 2007) :

1. Spécifique : tous les cadres n'ont pas été conçus pour aborder tous les problèmes. Ils devraient fournir un processus pour travailler sur les questions spécifiques à aborder.

2. Conceptuellement solide : basé sur la science et la théorie actuelles.

3. Pratique : dans le contexte de la capacité de l'organisation, le personnel a besoin d'un ensemble adéquat de compétences et de connaissances techniques pour utiliser et appliquer le cadre. Le personnel doit réfléchir à l'échelle des systèmes afin de tenir compte des conséquences ou des effets régionaux à différentes échelles de temps.

4. Éthique : les discussions devront permettre de comprendre qui bénéficie des décisions et qui peut en payer les coûts. Le processus doit être ouvert et délibératif pour permettre aux intervenants de participer aux discussions, dans un environnement sûr.

5. Pragmatique : permettre des résultats efficients et efficaces afin que des ressources humaines et financières puissent être allouées pour aborder les questions 


\section{Étude de cas 23.2 Principes de développement touristique d'un groupe autochtone : un exemple en Colombie-Britannique, Canada}

La communauté des Premières Nations Gitga'at, de Hartley Bay, sur la côte nord de la Colombie-Britannique (Canada), et l'Institut des ressources naturelles de l'Université du Manitoba ont collaboré à des recherches portant sur les points de vue des communautés sur le développement touristique. Une proposition communautaire visant à aller de l'avant avec le développement du tourisme a fourni aux membres de la communauté une plateforme pour réfléchir à leurs expériences en relation avec les développements touristiques existants, et discuter et identifier un ensemble de principes visant à guider les développements futurs. Nous avons constaté que les membres de la communauté considèrent que les aménagements touristiques sont appropriés et souhaitables, mais seulement s'ils soutiennent et améliorent la santé de leurs terres, de leurs habitants et de leur mode de vie.

Les Gitga'at voient que leur bien-être dépend de la santé écologique de leurs terres et de leur eau, soutenue par leur gestion de la terre et de la mer. Pour que ces relations soient solides, des opportunités permettant aux travailleurs et à leurs familles de demeurer sur le territoire, plutôt que de déménager dans des centres urbains hors réserve, doivent être créées. Comme l'a exprimé un membre de la communauté, " un certain nombre de choses sont Gitga'at, précieuses pour les Gitga'at, et aucune d'entre elles ne peut être compromise ». Par conséquent, un juste équilibre doit être trouvé entre l'intégrité culturelle, communautaire et écologique au moment d'analyser les types d'activités de développement économique local souhaitables. Des principes de développement du tourisme ont été tirés de tout cela, tous gravitant autour d'un thème simple et puissant : « nous voulons vivre ici » :

- Intégrité culturelle : les chefs et clans traditionnels doivent participer à la prise de décisions, et l'utilisation commerciale des ressources est plus adaptée lorsqu'elle est liée aux pratiques et modes de vie traditionnels.

- Intégritécommunautaire: les opportunitéséconomiques à faible impact devraient être exploitées, mais la plupart des bénéfices du développement devraient revenir aux Gitga'at et devraient être répartis équitablement au sein de la communauté.

- Intégrité écologique : les autres espèces doivent être respectées et les impacts écologiques du développement doivent être minimisés.

Un certain nombre de mécanismes à l'appui de ces principes furent également identifiés :

- assurer le contrôle et la gestion locale de toute entreprise ;

- organiser le partage des avantages de manière équitable, raisonnable et transparente ;

- $\quad$ établir des protocoles et autres accords, en particulier avec des chercheurs invités, pour protéger les ressources et les connaissances Gitga'at ;

- $\quad$ entreprendre un suivi et une évaluation soigneux et réguliers des impacts sociaux et écologiques de toute activité touristique, parallèlement à un processus significatif et continu de consultation locale ;
- faciliter des relations interculturelles respectueuses entre les visiteurs et les membres de la communauté, grâce à l'interprétation et au soutien des visiteurs par les guides Gitga'at ;

- $\quad$ établir des zones « interdites » pour les visiteurs, afin de protéger la vie privée de la communauté et de mieux assurer la sécurité des ressources locales, y compris les connaissances (par exemple, les informations concernant les plantes médicinales) et les espaces physiques (par exemple, les lieux de récolte et les lieux spéciaux, tels que les sépultures).

Les chercheurs ont identifié ces mécanismes comme des moyens importants de protéger le bien-être des Gitga'at et de leur territoire, y compris le maintien du flux d'informations et du dialogue nécessaires pour adapter les services touristiques afin de mieux refléter les besoins et intérêts de la communauté. Lors de l'analyse de ces principes, de nombreuses personnes dans la communauté ont tiré parti de leur expérience avec les entreprises touristiques passées ou existantes dans la région, y compris l'observation de la faune, les visites culturelles du village de Hartley Bay, la pêche sportive et les éco-lodges. Un faible impact écologique, la participation et l'emploi des membres de la communauté, et des entreprises fonctionnant conformément aux protocoles culturels Gitga'at, y compris le respect de l'autorité décisionnelle des dirigeants traditionnels et locaux, ont été considérés comme des caractéristiques souhaitables de certains de ces exemples. La capacité de générer davantage de bénéfices culturels, économiques et écologiques pour les Gitga'at grâce à des contrôles locaux est toutefois apparue comme une priorité pour le tourisme futur.

Le projet a révélé que de nombreux Gitga'at considèrent ce tourisme fondé sur des principes comme un forum, associé à un nouveau type de motivation, dans lequel les jeunes et autres membres de la communauté apprennent à connaître la culture et les modes de vie Gitga'at, y compris la langue Sm'algyax, les compétences de récolte et de transformation des aliments, les connaissances écologiques traditionnelles, et autres compétences importantes sur le plan culturel. Comme un membre de la communauté l'a expliqué : "Nous avons besoin de quelqu'un pour pouvoir raconter l'histoire de notre peuple... et inversement, cette expertise qui pourrait être développée, pourrait être utilisée ici quand nous recevons des touristes ".

Katherine L. Turner 
prioritaires, et surtout, pour que les impacts puissent effectivement être pris en compte.

Bien que l'accent soit mis sur ces cadres formels, il est reconnu que le personnel de terrain et les communautés locales appliquent souvent des cadres et des pratiques informels qui leur permettent de comprendre les relations dynamiques en jeu. Ceux-ci incluent notamment des observations quotidiennes, enregistrées ou rapportées de manière informelle, une rétroaction occasionnelle des/vers les communautés locales et le personnel, une réflexion et une discussion sur les approches alternatives à la réalisation de projets incluant l'analyse des avantages et des inconvénients, et autres pratiques. Dans ce chapitre, nous considérons sept cadres de gestion des visiteurs :

- la capacité de charge ;

- les limites de changement acceptable ;

- les processus de gestion des activités des visiteurs et d'évaluation des activités appropriées ;

- le modèle d'impact des visiteurs ;

- l'expérience des visiteurs et la protection des ressources;

- le modèle de gestion de l'optimisation touristique ;

- le cadre valeurs-menaces.

\section{Capacité de charge ;}

Le concept de capacité de charge remonte aux années 1950 et 1960 , lorsque les aires sauvages américaines ont connu une forte augmentation des loisirs de plein air, et qu'une inquiétude grandissait autour de la sur-fréquentation et de niveaux d'utilisation appropriés. La capacité de charge a été définie de différentes manières (tableau 23.8).

La capacité de charge est un concept central qui sous-tend de nombreux cadres d'impact des visiteurs. Il s'agit d'un concept facile à comprendre et qui peut s'avérer plus simple, moins coûteux et plus réalisable à mettre en œuvre que d'autres cadres (Farrell et Marion, 2002). Il continue aujourd'hui de recevoir une attention significative de la part des chercheurs universitaires et des organismes publics de gestion des terres. Cette approche présente toutefois de sérieuses limites. Il s'agit essentiellement d'un concept restrictif, fondé sur des limites et des contraintes. Bien que cela puisse convenir à des questions très spécifiques telles que la gestion des aires de reproduction de la faune, des grottes et autres sites sensibles, il peut également être considéré comme allant à l'encontre des objectifs des aires protégées, conçues pour encourager la jouissance et la valorisation appropriées des aires protégées par les visiteurs. Les chercheurs ont identifié des problèmes importants dans sa formulation, sa validité conceptuelle et son utilité pour la gestion :

- la capacité de charge exige des objectifs précis, mais les organismes sont souvent réticents à élaborer de tels objectifs ;

- parce que la capacité de charge est une fonction des objectifs, il existe beaucoup de capacités de charge pour un même site, et de ce fait, le concept perd de son utilité ;

- dans la plupart des situations de gestion des loisirs, les problèmes d'impact dépendent davantage du comportement des visiteurs ou de mesures de développement que de chiffres ;

- il existe souvent une confusion, dans la littérature, au sujet de la nomenclature : capacité de charge, politiques de limite d'utilisation et processus tels que les limites de changement acceptable ;

- les conditions nécessaires pour établir une capacité de charge ne sont souvent pas présentes sur un site de loisirs ;

- parce que la capacité de charge est une approche technique de problèmes fondamentalement chargés de valeur, elle ne laisse que peu de place à la participation du public (McCool et al., 2007:40-3).

De plus, une prémisse importante sous-jacente à la notion de capacité de charge est que le site naturel préoccupant est stable et immuable (McCool et al., 2007). Il est

Tableau 23.8 Définitions de la capacité de charge

\begin{tabular}{|l|l|}
\hline Aspect & Définition \\
\hline Loisirs & Le niveau d'utilisation au-delà duquel la ressource récréative ou l'expérience récréative se détériore. \\
\hline Biophysique & $\begin{array}{l}\text { Le nombre maximum de personnes pouvant utiliser un site donné pour une période spécifiée sans } \\
\text { réduire la capacité de ce site à soutenir l'utilisation. }\end{array}$ \\
\hline Social & $\begin{array}{l}\text { Le nombre maximum de personnes pouvant utiliser un site donné pour une période spécifiée sans } \\
\text { réduire le niveau de satisfaction reçu par chaque personnes sur le site. }\end{array}$ \\
\hline Gestion & $\begin{array}{l}\text { Le nombre maximal de personnes pouvant être hébergées sur un site donné pour une période } \\
\text { déterminée : a) sans dégrader l'environnement au-delà d'un niveau d'acceptabilité donné, b) sans } \\
\text { causer d'impacts socioculturels et économiques inacceptables sur la population locale, et c) en } \\
\text { fournissant un niveau de satisfaction donné pour un pourcentage donné des utilisateurs, tels que } \\
\text { définis par les objectifs de gestion des loisirs de ce site. }\end{array}$ \\
\hline
\end{tabular}


toutefois reconnu que les systèmes biologiques et sociaux sont dynamiques, complexes et remplis d'incertitudes. Les changements induits par l'homme, raison d'être de la capacité de charge, peuvent être cachés par des variations naturelles telles que celles causées par le climat, les incendies et les inondations. Par conséquent, lorsque des capacités de charge fixes sont établies dans des conditions fluctuantes, leur validité est remise en question.

D'autres chercheurs concluent que la capacité de charge a été trop simplifiée dans la pratique, qu'elle met trop l'accent sur la limitation de l'utilisation par les visiteurs alors que d'autres paramètres pourraient être ajustés, qu'elle n'a pas réussi à minimiser les impacts des visiteurs dans certains cas, et qu'elle n'a pas intégré la participation du public ou les besoins locaux en ressources (Farrell et Marion, 2002).

\section{Limites de changement acceptable}

Le cadre des " limites de changement acceptable " (LCA) (Stankey et al., 1984) s'appuie sur le concept du SOL. Comme celui-ci, il identifie une variété d'expériences de loisirs dans différents contextes, mais contrairement au SOL, il est axé sur les problèmes (Haider et Payne, 2009). Il comprend la participation des parties prenantes à l'ensemble du processus, y compris l'établissement des normes relatives à la quantité et à l'étendue des changements induits par l'homme jugés acceptables pour un site. Le processus identifie également les remèdes que les gestionnaires devraient offrir. La sélection d'indicateurs et de normes mesurables, et leur suivi postérieur, est une étape clé, car elle fournit la base pour définir si une condition est acceptable ou non. Il s'agit toutefois de tâches difficiles, qui exigent des capacités techniques et du temps, et qui peuvent donc être coûteuses à mettre en œuvre (Brown et al., 2006; de Lacy et Whitmore, 2006). En fonction des objectifs de gestion, des indicateurs physiques, biologiques et sociaux peuvent être choisis.

Le cadre LCA a été appliqué partout dans le monde. Il est mieux adapté à l'échelle des paysages, et a été intégré au cadre "Expérience des visiteurs et protection des ressources " (EVPR) (Haider et Payne, 2009). Le cadre LCA comprend neuf étapes permettant de déterminer les ressources et conditions sociales les plus importantes et les plus acceptables :

1. Identifier les préoccupations et les enjeux du site.

2. Définir et décrire les classes d'opportunités (basées sur le concept du SOL).

3. Sélectionner des indicateurs de ressources et de conditions sociales.

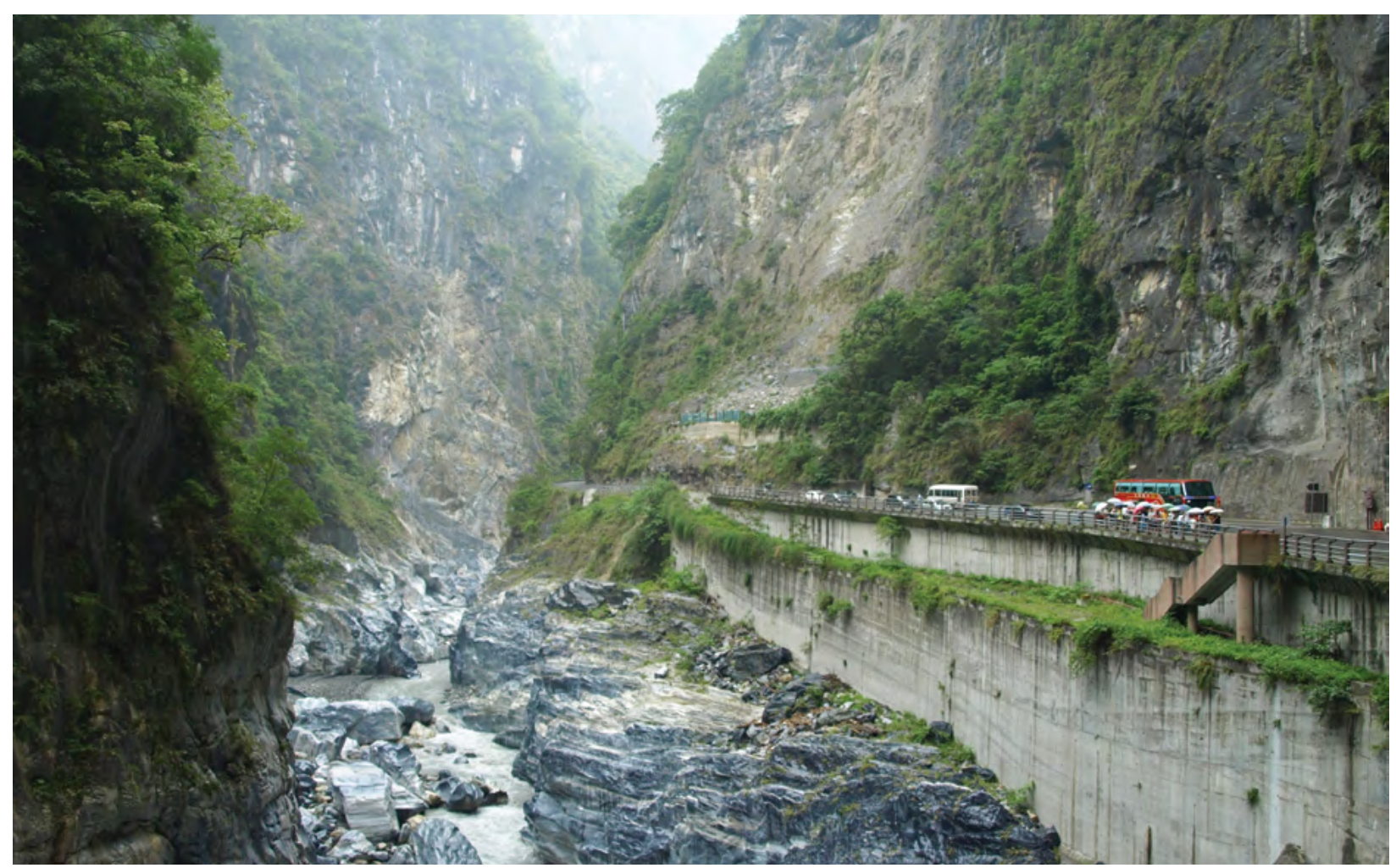

Visiteurs contemplant la spectaculaire gorge de la rivière Liwu, parc national de Taroko, Taiwan. Ce site est également connu sous le nom de « Gorge de marbre » du fait de l'incision de la rivière dans la roche calcaire métamorphosée

Source : Graeme L. Worboys 
4. Réaliser un inventaire des ressources et des conditions sociales existantes.

5. Préciser des normes pour les indicateurs sociaux et de ressources pour chaque classe d'opportunités.

6. Identifier les affectations de classes d'opportunités alternatives.

7. Identifier les mesures de gestion pour chaque solution alternative.

8. Évaluer et sélectionner les solutions alternatives les plus adaptées.

9. Mettre en œuvre les mesures et réaliser un suivi des conditions (Stankey et al., 1984).

\section{Processus de gestion des activités des visiteurs et d'évaluation des activités appropriées}

Le « processus de gestion des activités des visiteurs » (PGAV) a été élaboré par Parcs Canada à la fin des années 1980. Il combine les principes des sciences sociales à ceux du marketing pour se concentrer sur l'analyse des opportunités plutôt que sur l'impact des visiteurs. Il est particulièrement utile pour prendre des décisions stratégiques et opérationnelles au sujet des marchés cibles et de la position de marché, et pour déterminer les activités d'interprétation et de loisirs, ainsi que les installations de service appropriées (Brown et al., 2006). Les étapes du processus PGAV sont les suivantes :

1. Établir le mandat du projet.

2. Confirmer les énoncés actuels des buts et objectifs du parc.

3. Organiser une base de données décrivant les écosystèmes et les paramètres du parc, les options éducatives et récréatives potentielles pour les visiteurs, les activités et services existants pour les visiteurs et le contexte régional.

4. Analyser la situation actuelle afin de déterminer les thèmes patrimoniaux, la capacité et la pertinence des ressources, les activités appropriées pour les visiteurs, le rôle du parc dans la région et le rôle du secteur privé.

5. Produire des concepts d'activité des visiteurs alternatifs pour ces contextes, expériences à soutenir, segments de marché des visiteurs, niveaux de lignes directrices de service, et rôles de la région et du secteur privé.

6. Élaborer un plan de gestion du parc incluant le but et le rôle du parc, les objectifs et lignes directrices de gestion, les relations régionales et le rôle du secteur privé.

7. Établir des priorités pour la conservation du parc et la planification des services du parc, puis mettre en œuvre le plan (Brown et al., 2006).
Le PGAV a une capacité exceptionnelle, et a été utilisé pour comprendre et gérer l'utilisation par les humains, évaluer et gérer les risques et déterminer les activités appropriées dans les parcs nationaux du Canada (Haider et Payne, 2009). Le PGAV a évolué en une "Évaluation des activités appropriées "(EAA), qui reconnaît que tous les types d'activités ne sont pas appropriées dans les aires protégées. Selon les principes suivants de l'EAA, les activités récréatives dans les parcs nationaux, les lieux historiques nationaux et les aires marines nationales de conservation du Canada doivent :

- préserver ou améliorer le caractère du lieu ;

- respecter les ressources naturelles et culturelles;

- faciliter les opportunités d'expériences exceptionnelles pour les visiteurs ;

- promouvoir la compréhension et l'appréciation du public ;

- valoriser et impliquer les communautés locales (Haider et Payne, 2009).

Le PGAV est basé sur le SOL et conçu pour la planification régionale. Il peut facilement intégrer les principes des cadres de LAC, GIV et EVPR.

\section{Gestion de l'impact des visiteurs}

Le cadre de "Gestion de l'impact des visiteurs " (GIV) a été développé par des chercheurs de la National Parks and Conservation Association, basée aux États-Unis. Il aborde trois questions liées à l'impact des visiteurs, à savoir : 1) conditions problématiques ; 2) facteurs de causalité potentiels ; 3) stratégies potentielles de gestion (Nilsen et Tayler, 1998). Le processus fait appel à la fois à la science et, surtout, au jugement professionnel, et met l'accent sur la nécessité de comprendre les facteurs de causalité lors de l'identification des stratégies de gestion. Pour aborder les impacts des visiteurs, le GIV est lié à la capacité de charge écologique et sociale. Comme le montrent les étapes ci-après, les gestionnaires doivent préciser les normes écologiques et de suivi des aires protégées (Haider et Payne, 2009). Le processus GIV comporte huit étapes clés :

1. Réaliser une analyse préalable des bases de données.

2. Évaluer les objectifs de gestion.

3. Sélectionner des indicateurs d'impact clés.

4. Sélectionner des normes pour les indicateurs d'impact clés.

5. Comparer les normes et les conditions existantes.

6. Identifier les causes probables des impacts.

7. Identifier les stratégies de gestion.

8. Mettre en œuvre la stratégie (Nilsen et Tayler, 1998). 
Le GIV est une variante du LCA et a été incorporé dans le processus EVPR (Brown et al., 2006). Il est plus approprié dans les situations où moins de ressources sont disponibles pour le suivi.

\section{Expérience des visiteurs et protection des ressources}

Développée par le Service des parcs nationaux des ÉtatsUnis, la méthode "Expérience des visiteurs et protection des ressources » (EVPR) intègre les problèmes de capacité de charge sociale et écologique à des indicateurs et normes de qualité (Haider et Payne, 2009). Le processus met l'accent sur un zonage spatial visant à intégrer les ressources et les conditions sociales, ce qui peut constituer une entreprise difficile. L'EVRP s'appuie sur les cadres de LCA et de PGAV et comprend neuf étapes :

1. Constituer une équipe de projet interdisciplinaire.

2. Élaborer une stratégie de participation du public.

3. Élaborer des énoncés de l'objet, l'importance et les principaux thèmes d'interprétation du parc, et déterminer les mandats et contraintes en matière de planification.

4. Analyser les ressources du parc et l'utilisation actuelle des visiteurs.

5. Décrire une gamme potentielle d'expériences pour les visiteurs et de conditions de ressources (zones potentielles de prescription).

6. Attribuer les zones potentielles à des endroits précis dans le parc (zonage de gestion prescriptif).

7. Choisir des indicateurs et préciser des normes pour chaque zone, et élaborer un plan de suivi.

8. Réaliser un suivi des ressources et des indicateurs sociaux.

9. Prendre des mesures de gestion (Haider et Payne, 2009).

\section{Modèle de gestion de l'optimisation touristique}

Le "Modèle de gestion de l'optimisation touristique" (MGOT) a été développé en Australie dans les années 1990 pour la planification du tourisme régional, qui incluait les aires protégées (McArthur, 1999). Il vise à suivre et à quantifier les avantages et impacts des activités touristiques, et à évaluer les problèmes émergents et les solutions alternatives pour un tourisme futur durable (Brown et al., 2006). Bien que le modèle soit basé sur le processus de LCA, son nom prétend éviter la connotation négative des « limites ». Le MGOT étend le concept de LCA aux parcs et communautés riveraines en tenant compte des intérêts commerciaux et communautaires à toutes les étapes de la mise en œuvre et du suivi (Haider et Payne, 2009). Les points forts de ce modèle incluent son application au contexte des environnements économiques, politiques et sociaux dans lesquels le tourisme opère, ainsi que la participation des parties prenantes tout au long du processus. Compte tenu de sa couverture plus vaste, il nécessite beaucoup d'informations et donc, des ressources importantes pour la gestion des données et un engagement à long terme de la part d'un large éventail de parties prenantes. Le cadre MGOT comprend cinq dimensions :

- économique (contribution financière de l'activité touristique);

- opportunités de marché (caractéristiques clés du profil de marché et activité de marketing);

- expérientielle (la nature de l'expérience principale offerte aux visiteurs) ;

- communautaire (la qualité de vie des résidents locaux et des autochtones ayant un lien avec la région);

- environnementale (l'environnement biophysique, allant de la biodiversité et des conditions de la faune aux modes de consommation d'énergie) (McArthur, 1999).

Le MGOT comprend six étapes :

1. Planifier le processus et commencer la participation des parties prenantes en identifiant ces parties prenantes et en générant des scénarios touristiques.

2. Compiler et écrire une description de contexte décrivant la situation actuelle. Évaluer les documents de planification et de politique pour la région. Poursuivre la participation des parties prenantes et commencer l'engagement en organisant une séance d'information avec les parties prenantes.

3. Élaborer un programme de suivi qui identifie ce qu'il faut mesurer et comment le faire, et qui définisse les normes de déclaration. Rédiger un ensemble de conditions optimales et étudier les indicateurs associés.

4. Peaufiner la description du contexte et le programme de suivi à partir d'un atelier avec les parties prenantes. Réduire le nombre d'indicateurs, en déterminant la fourchette acceptable et le point de référence pour chacun.

5. Préparer l'ébauche et la version finale d'un plan de MGOT, et informer les parties prenantes.

6. Mettre en œuvre et affiner le modèle. Commencer le suivi. Après le premier cycle, identifier les indicateurs en dehors de la fourchette acceptable, et identifier les possibles relations de cause à effet pour élaborer des réponses de gestion. Le processus itératif se poursuit avec le perfectionnement continu des indicateurs, des conditions optimales et des fourchettes (McArthur, 1999). 


\section{Cadre valeurs-menaces}

Une autre approche pour aborder les impacts des visiteurs est l'application d'approches valeurs-menaces, dans lesquelles les valeurs naturelles de l'aire protégée servent de base pour analyser les menaces à leur viabilité. Les Normes ouvertes pour la pratique de la conservation (CMP, 2013) fournissent un cadre robuste et général pour la planification, la gestion et le suivi axés sur les résultats, ancré dans les concepts de planification et de gestion adaptatives (voir le chapitre 13). Paleczny (2010) a adapté et appliqué ce cadre à un contexte plus général, en Égypte, pour aborder explicitement les valeurs non liées à la biodiversité, c'est à dire les valeurs culturelles, récréatives, touristiques et de bien-être des communautés locales. Le "Cadre de gestion des impacts des visiteurs des aires protégées " (Farrell et Marion, 2002) a utilisé des éléments du cadre des normes ouvertes en Amérique centrale et en Amérique du Sud.

\section{Conclusion}

L'utilisation par les visiteurs et l'utilisation officielle des aires protégées font partie intégrante de leur gestion. Les types communs d'utilisation par les visiteurs des six catégories différentes d'aires protégées de l'UICN ont été identifiés, ainsi que leurs implications pour la gestion de cette utilisation. Le tourisme est peut-être l'utilisation la plus importante des aires protégées, et les nombreux aspects de la gestion du tourisme dans ces sites spéciaux ont été décrits. Il est très important de travailler en partenariat avec l'industrie du tourisme. Une base de travail entre les gestionnaires d'aires protégées et l'industrie du tourisme, et les avantages potentiels qu'une telle collaboration représente ont été décrits. L’objectif principal de ce chapitre était de fournir une gamme d'outils et de conseils aux gestionnaires d'aires protégées pour les aider à préserver les conditions naturelles à long terme des destinations des visiteurs des aires protégées, comme base pour la conservation de la biodiversité et du patrimoine, et par conséquent, pour une utilisation véritablement durable par les visiteurs. 


\section{Références}

Lectures recommandées

Aaker, D. A. (1995) Strategic Market Management, Wiley, New York.

Aaker, J. L. (1997) 'Dimension of brand personality', Journal of Marketing Research 34(1): 347-56.

Baker, B. (2012) Destination Branding for Small Cities: The essentials for successful place branding, 2nd edn, Creative Leap Books, Portland, OR.

British Columbia Ministry of Forests (1991) Recreation Manual, Ministry of Forests, British Columbia, Canada. <www.for.gov.bc.ca/hfp/ publications/00201/>

Brown, G., Koth, B., Kreag, G. et Weber, D. (2006) Managing Australia's Protected Areas: A review of visitor management models, frameworks and processes, Sustainable Tourism Cooperative Research Centre, Griffith University, Gold Coast, Queensland.

Buckley, R. (2006) Adventure Tourism, CAB International, Wallingford, Royaume-Uni.

Buckley, R. (2010) Conservation Tourism, CAB International, Wallingford, Royaume-Uni.

DD Buckley, R., Pickering, C. M. et Weaver, D. (eds) (2003) Nature-Based Tourism, Environment and Land Management, CAB International, Cambridge.

Butler, R. W. (1980) 'The concept of a tourism area life cycle of evolution: implications for management of resources', The Canadian Geographer 24(1): 5-12.

Chee, C. G., Makens, J. C. et Choy, D. J. L. (1997) The Travel Industry, 3rd edn, van Nostrand Reinhold, New York.

Clark, R. N. et Stankey, G. H. (1979) The Recreation Opportunity Spectrum: A framework for planning, management, and research, General Technical Report PNW-98, US Department of Agriculture Forest Service, Washington, DC.

Cole, D. N. et Williams, D. R. (2012) 'Wilderness visitor experiences: a review of 50 years of research', in D. N. Cole (ed.) Wilderness Visitor Experiences: Progress in research and management, 2011 April 4-7; Missoula, Montana, Proceedings, RMRS-P-66, pp. 3-20, US Department of Agriculture Forest Service, Rocky Mountain Research Station, Fort Collins, CO.
Commonwealth of Australia (CoA) (1991) Ecologically Sustainable Working Groups: Final report, Commonwealth of Australia, Canberra.

Conservation Measures Partnership (CMP) (2013) The Open Standards for the Practice of Conservation. <www. conservationmeasures.org/>

de Lacy, T. et Whitmore, M. (2006) 'Tourism and recreation', in M. Lockwood, G. L. Worboys et Kothari (eds) Managing Protected Areas: A global guide, pp. 497-527, Earthscan, Londres.

Dibb, S. et Simkin, L. (2009) 'Implementation rules to bridge the theory/practice divide in market segmentation', Journal of Marketing Management 25(3-4): 375-96.

Driver, B. L. et Brown, P. J. (1978) 'The opportunity spectrum concept and behaviour information in outdoor recreation resource supply inventories: a rationale', in H. G. Lund, V. J. LaBau, P. F. Folliott et D. W. Robinson (eds) Integrated Inventories of Renewable Natural Resources: Proceedings of the workshop, General Technical Report RM- 55, pp. 24-31, US Department of Agriculture.

Forest Service, Rocky Mountain Forest and Range Experimental Station, Fort Collins, CO.

Driver, B., Nash, R. et Haas, G. (1987) 'Wilderness benefits: a state-of-knowledge review', in R. C. Lucas (ed.) Proceedings: National Wilderness Research Conference issues, state-of-knowledge, future directions, General Technical Report INT-220, pp. 294-319, US Department of Agriculture Forest Service Intermountain Research Station, Ogden, UT.

Dudley, N. (2008) Guidelines for Applying Protected Area Categories, IUCN, Gland. <www.iucn.org/ pa_ categories>

Eagles, P. F. J., McCool, S. F. et Haynes, C. D. A. (2002) Sustainable Tourism in Protected Areas: Guidelines for planning and management, UICN, Gland.

Dagles, P. et Legault, K. M. (2013) Guidelines for the Planning and Management of Concessions, Leases, Licenses, and Permits in Parks and Protected Areas, University of Waterloo, Ontario.

Elkington, J. (1997) Cannibals with Forks: The triple bottom line of 21st century business, Capstone, Oxford. 
Emerton, L., Bishop, J. et Thomas, L. (2006a) Best Practice Protected Area Guidelines Series, No. 013, IUCN World Commission on Protected Areas, James Cook University, Queensland.

Emerton, L., Bishop, J. et Thomas, L. (2006b) Sustainable Financing of Protected Areas: A global review of challenges and options, UICN, Cambridge.

Farrell, M. et Marion, J. L. (2002) 'The protected area visitor impact management (PAVIM) framework: a simplified process for making management decisions', Journal of Sustainable Tourism 10: 31-51.

Font, X., Cochrane, J. et Tapper, R. (2004) Tourism for Protected Area Financing: Understanding tourism revenues for effective management plans, Leeds Metropolitan University, Leeds.

Frangialli, F. (2001) 'World Tourism organization perspectives on the International Year of Ecotourism', Industry and Environment 24(3-4) (July-December): 4. <www.uneptie.org/media/ review/vol24no3-4/ UNEP_p1_49.pdf>

Goodwin, H. (1996) 'In pursuit of ecotourism', Biodiversity and Conservation 5: 277-92.

Haider, W. et Payne, R. J. (2009) 'Visitor planning and management', in P. Dearden and R. Rollins (eds) Parks and Protected Areas in Canada, 3rd edn, Oxford University Press Canada, Don Mills, Ontario.

Hall, C. M. et McArthur, S. (1998) Integrated Heritage Management: Principles and practice, The Stationery Office, Londres.

Ham, S. (2013) Interpretation: Making a difference on purpose, Fulcrum Publishing, Golden, CO.

D. Higginbottom, K., Carter, R. W., Moore, S., Rodger, K. et Narayanan, Y. (2010) Current Practices in Monitoring and Reporting on Sustainability of Visitor Use of Protected Areas, Sustainable Tourism Cooperative Research Centre, Griffith University, Gold Coast, Queensland.

Hunt, S. D. et Arnett, D. B. (2004) 'Market segmentation strategy, competitive advantage, and public policy: grounding segmentation strategy in resource-advantage theory', Australian Marketing Journal 12(1): 7-25.

Kohl, J. (2007) 'Dodging cuts: surviving budget cuts for heritage interpretation means becoming relevant', Parks and Recreation Magazine, March. <www.jonkohl.com/ publications/a-m/avoid-cuts. htm>
Kotler, P. (2003) Marketing Management, 11th edn, Prentice Hall, Upper Saddle River, NJ.

Liddle, M. (1997) Recreation Ecology, Chapman \& Hall, Londres.

Lockwood, M., Worboys, G. L. et Kothari, A. (2006) Managing Protected Areas: A global guide, 2nd edn, Earthscan, Londres.

McArthur, S. (1999) Visitor management in action: an analysis of the development and implementation of visitor management models at Jenolan Caves and Kangaroo Island, $\mathrm{PhD}$ thesis, University of Canberra, Canberra.

McCool, S. F., Clark, R. N. et Stankey, G. H. (2007) An assessment of frameworks useful for public land recreation planning, General Technical Report PNW-GTR-705, US Department of Agriculture Forest Service, Pacific Northwest Research Station, Portland, OR.

Manning, R. E. (1985) 'Diversity in a democracy: expanding the recreation opportunity spectrum', Leisure Sciences 7(4): 377-99.

Melbourne Business Community (2013) News: Business events in Northern Territory. <www. melbournebusinesscommunity.com.au/2013/07/ business-events-in-the-northern-territory>

Monz, C. A., Pickering, C. M. et Hadwen, W. L. (2013) 'Recent advances in recreation ecology and implications of different relationships between recreation use and ecological impacts', Frontiers in Ecology and Environment 11(8): 441-6.

Dewsome, D., Moore, S. A. and Dowling, R. K. (2002) Natural Area Tourism: Ecology, impacts and management, Channel View, Clevedon, Royaume-Uni.

Nilsen, P. et Taylor, G. (1997) 'A comparative analysis of protected area planning and management frameworks', Proceedings_Limits of Acceptable Change and Related Planning Processes: Progress and Future Directions, pp. 49-57, General Technical Report INT-GTR-371, United States Department of Agriculture, Forest Service, Intermountain Research Station, Ogden, UT.

Ontario Parks (2005) A Class Environmental Assessment for Provincial Parks and Conservation Reserves, Ontario Ministry of Natural Resources, Peterborough.

Pacey, L. (2013) The Lure of Montague, 3rd edn, Laurelle Pacey, Narooma, NSW. 
Paleczny, D. R. (2010) Protected area assessment and reporting: an examination of current approaches and evolving needs with application of an integrated model in Egypt, PhD dissertation, University of Greenwich and International Centre for Protected Landscapes, Royaume-Uni.

Phillips, A. (2000) Financing Protected Areas: Guidelines for protected area managers, UICN, Cambridge.

Pine, B. J. II et Gilmore, J. H. (1999) The Experience Economy: Goods and services are no longer enough: Work is theatre and every business is a stage, Harvard Business School Press, Cambridge, MA.

Priskin, J. et McCool, S. F. (2006) 'The visitor experience challenge', [Editorial], Parks: The International Journal for Protected Areas Managers 16(2): 65.

Reid, M., Wearing, S. et Croy, G. (2008) Marketing of Protected Areas as a Tool to Influence Visitors' Pre-Visit Decisions, Sustainable Tourism Cooperative Research Centre, Griffith University, Gold Coast, Queensland.

Shafer, E. L. (1969) The average camper who doesn't exist, US Department of Agriculture Forest Service Research Paper NE-142, Northeastern Forest Experiment Station, Upper Darby, PA.

South African National Parks (SANParks) (2011) 'Tourism sales and marketing report', in 2010-2011 Annual Report, pp. 18-27, SANParks, Pretoria.

Stankey, G. H., McCool, S. F. et Stokes, G. L. (1984) 'Limits of acceptable change: a new framework for managing the Bob Marshall Wilderness complex', Western Wildlands 103(3): 33-7.

Swarbroke, J. (1988) Sustainable Tourism Management, CAB International, New York.

The International Ecotourism Society (TIES) (2014) What is Ecotourism? The International Ecotourism Website. <www.ecotourism.org/what-is-ecotourism>

Tourism Australia (2010) Ningaloo-Shark Bay: A guide to making the most of your landscape positioning, Australia's National Landscapes Program, Canberra.

Tourism Australia (2012) Experience Development Strategies: Guidelines for Australia's National Landscape Steering Committee, 2nd edn, Australian Government Director of National Parks, Canberra.
Tropical Science Centre (TSC) (2014) Monteverde Cloud Forest Reserve Educational Programmes, Tropical Science Centre, San José, Costa Rica. <www. reservamonteverde.com/programs.html\#2>

Turner, K. L., Berkes, F. et Turner, N. J. (2012) 'Indigenous perspectives on ecotourism development: a British Columbia case study', Journal of Enterprising Communities, Special Issue: Indigenous communities, the bioeconomy and natural resource development 6(3): 213-29.

Tynan, C. et Drayton, J. (1987) 'Market segmentation', Journal of Marketing Management 2(3): 301-35.

United Nations (UN) (1992) Agenda 21, Earth Summit, United Nations, New York. <www. un.org/esa/sustdev/ documents/agenda21/english/ agenda21chapter1. htm12>

United Nations (UN) (1997) Agenda for Development, United Nations, New York.

United Nations Educational, Scientific and Cultural Organisation (UNESCO) (2011) Operational Guidelines for the Implementation of the World Heritage Convention, UNESCO, Paris.

United Nations Environment Programme (UNEP) (2005) Forging Links between Protected Areas and Tourism Sector: How tourism can benefit conservation, UNEP, Paris.

United Nations Environment Programme (UNEP) and United Nations World Tourism Organisation (UNWTO) (2005) Making Tourism More Sustainable: A guide for policy makers, UNWTO, Madrid.

United Nations World Tourism Organisation (UNWTO) (1995) Technical Manual. Number 2: Collection of tourism expenditure statistics, UNWTO, Madrid.

United Nations World Tourism Organisation (UNWTO) (2012) Summary: Study on tourism and intangible cultural heritage, UNWTO, Madrid. <dtxtq4w60xqpw. cloudfront.net/sites/all/files/ docpdf/summaryview.pdf>

United Nations World Tourism Organisation (UNWTO) (2014a) Understanding Tourism: Basic glossary, UNWTO, Madrid. < media.unwto.org/en/ content/ understanding-tourism-basic-glossary>

United Nations World Tourism Organisation (UNWTO) (2014b) World Tourism Barometer, UNWTO, Madrid. $<$ dtxtq4w60xqpw.cloudfront. net/sites/all/files/pdf/ unwto_barom14_02_apr_excerpt.pdf> 
Wearing, S., Archer, D. et Beeton, S. (2007) The Sustainable Marketing of Tourism in Protected Areas: Moving forward, Sustainable Tourism Cooperative Research Centre, Griffith University, Gold Coast, Queensland.

Weaver, D. et Lawton, L. (2002) Tourism Management, 2nd edn, John Wiley \& Sons, Brisbane.

Worboys, G. L. (2007) Evaluation subjects and methods required for managing protected areas, $\mathrm{PhD}$ thesis, Griffith University, Gold Coast Campus, Queensland.

Worboys, G. L., Lockwood, M. et de Lacy, T. (2005) Protected Area Management: Principles and practice, Oxford University Press, Melbourne.

Yankelovich, D. et Meer, D. (2006) 'Rediscovering market segmentation', Harvard Business Review 84(2): 112-31.

Yeo, G. (2005) 'Understanding users and use: a market segmentation approach', Journal of the Society of Archivists 26(1): 25-53. 
Ce texte est extrait du livre "Gouvernance et gestion des aires protégées " édité par Graeme L. Worboys, Michael Lockwood, Ashish Kothari, Sue Feary et Ian Pulsford, publié en 2020 par l'ANU Press, l'Australian National University, Canberra, Australie.

La reproduction de cette publication de l'ANU Press à des fins éducatives ou non commerciales est autorisée sans l'autorisation écrite préalable du détenteur des droits d'auteur, à condition que la source soit clairement indiquée. La reproduction de cette publication pour la revente ou à d'autres fins commerciales est interdite sans l'autorisation écrite préalable du détenteur des droits d'auteur. 